\title{
A New Evaluation Method for Antibiotic-Resistant Bacterial Groups in Environment
}

\author{
Katsuji Watanabe ${ }^{1}$, Naoto Horinishi', Kunimasa Matsumoto ${ }^{1}$, Akihiro Tanaka², \\ Kenichi Yakushido ${ }^{3}$ \\ ${ }^{1}$ Department of Life, Environment and Materials Science, Fukuoka Institute of technology, Fukuoka, Japan \\ ${ }^{2}$ National Agricultural Research Center for Kyushu-Okinawa Region, National Agriculture and Food Research \\ Organization, Kumamoto, Japan \\ ${ }^{3}$ National Agricultural Research Center, National Agriculture and Food Research Organization, Tsukuba, Japan \\ Email: "k-watanabe@fit.ac.jp
}

Received 31 January 2016; accepted 8 March 2016; published 11 March 2016

Copyright (C) 2016 by authors and Scientific Research Publishing Inc.

This work is licensed under the Creative Commons Attribution International License (CC BY).

http://creativecommons.org/licenses/by/4.0/

c) (i) Open Access

\section{Abstract}

In the present manuscript it was presented whether spreading of antibiotic resistant bacterial groups in environment could be monitored by our newly developed method by enumerating antibiotic resistant bacterial groups in various biological wastes and composts. Although the numbers were not so high, diverse kinds of colistin resistant bacteria $\left(25 \mathrm{mg} \cdot \mathrm{L}^{-1}\right)$ were included in row cattle feces $\left(1.78 \times 10^{4} \mathrm{MPN} \mathrm{g}^{-1}\right)$ and cattle feces manure $\left(>3.84 \times 10^{4} \mathrm{MPN}^{-1}\right)$. Compost originated from leftover food ( $\left.>44.8 \times 10^{4} \mathrm{MPN}^{-1}\right)$ and shochu lee $\left(>320 \times 10^{4} \mathrm{MPN}^{-1}\right)$ included higher numbers of chlortetracycline resistant Pseudomonas sp., $\left(25 \mathrm{mg} \cdot \mathrm{L}^{-1}\right)$, and row cattle feces included higher numbers of chlortetracycline resistant Enterobacteriacea $\left(15.7 \times 1^{4} \mathrm{MPN}^{-1}\right)$, which mostly consisted from Pantoea sp. or Xenorhobdus doucetiae. Numbers of multi drug resistant bacteria, resistant to $25 \mathrm{mg} \cdot \mathrm{L}^{-1}$ of ciprofloxacin, streptomycin, chloramphenicol, and ampicillin, were the highest in row cattle feces $\left(>143.6 \times 10^{4} \mathrm{MPN}^{-1}\right)$, followed by cattle feces manure (4.19 $\left.\times 10^{4} \mathrm{MPN}^{-1}\right)$, and shochu lee $\left(0.36 \times 10^{4} \mathrm{MPN}^{-1}\right)$, which included diverse kinds of bacterial group. The present results indicated that higher numbers of multi drug resistant bacteria were typically found in row cattle feces, and the method was found suitable to enumerate and identify them. These results suggested that the method might become their environmental risk evaluation method.

\section{Keywords}

Colistin Resistant Bacteria, Chlortetracycline Resistant Bacteria, Multi Drug Resistant Bacteria, Multiple Enzyme Restriction Fragment Length Polymorphism Analysis, The Most Probable

\footnotetext{
${ }^{*}$ Corresponding author.
}

How to cite this paper: Watanabe, K., Horinishi, N., Matsumoto, K., Tanaka, A. and Yakushido, K. (2016) A New Evaluation Method for Antibiotic-Resistant Bacterial Groups in Environment. Advances in Microbiology, 6, 133-151. 


\section{Number Method, Microchip Electrophoresis System}

\section{Introduction}

At present, spreading of antibiotic resistant bacteria is becoming a major public health problem in all over the world [1]. As the susceptibility tests using bacterial isolates, with respect to specific nosocomial bacteria, were indispensable not only to search effective antibiotic for patient but also to prevent their nosocomial infection, the method has been used as a standard surveillance method for their risk assessment [2]-[4]. However their spreading area was recently expanding over various environments, such as drinking water [5]-[7], or vegetables [8][10], or daily products [11]-[13], due to their overuse not only as therapeutic agent in human and veterinary medicine but also as growth promotor in animal husbandry [14] [15], and the susceptibility tests and taxonomy determinations must be broadly expanded over a large numbers of environmentally important bacterial groups in order to know what kinds of antibiotic bacteria will be numerically dominant and then has a higher environmental risk [5]-[11] [13] [15]-[18].

With respect to the antibiotic bacteria, their taxonomic positions had no relation to the antibiotic resistance which was irregularly evolved by acquiring diverse kinds of resistant genes. Therefore molecular-based analysis method could not be used for their risk assessment because bacterial phylogenetic positions estimated by the unculture-based community analysis methods, such as DGGE or t-RFLP or clone library sequencing or pyrosequencing [19], had no-relation to those of the resistant bacterial groups. Although sequence-based metagenomics [20] [21] and real time PCR [22]-[25] targeting resistant gene afforded the information of the diversity or copy numbers of the resistant gene, they had no relation to the phylogenetic positions nor phenotypic properties of the resistant bacterial groups.

As prime feature of resistant bacteria distinguished from susceptible one was an ability to survive and proliferate under antibiotic, which was also concerned with one of their risk, we thought that environmental risk of antibiotic resistant bacteria in might be evaluated by identifying and quantifying bacteria grown under application of antibiotic. Until now, we had presented a new method to provide numbers of each taxonomically different bacterial groups in the former papers [26] [27]. By the method, sample having simple microbial diversity such as food and aquatic sample could be analyzed without cultivation, that having the huge microbial diversity such as soil and manure required cultivation before analysis for exact phylogenetic estimation [26] [27]. In this manuscript, bacterial groups resistant to colistin, chlortetracycline, and multi drugs, in row cattle feces, cattle feces manure, shochu lee, and compost originated from leftover food were identified and enumerated by the method adding these antibiotics.

\section{Materials and Methods}

\subsection{Samples}

Row cattle feces (R), which would be converted into cattle feces manure, was collected from a cow barn for daily cattle in National Agricultural Research Center for Kyushu-Okinawa Region, where daily cattle were breeding in Japanese standard method [28]. Cattle feces manure (M) was provided from farmer around National Agricultural Research Center for Kyushu-Okinawa Region. Shochu lee (S), residual aqueous solution of sweet potato after fermentation and distillation of shochu, was obtained from Akashi Shuzo Co. Ltd. (Miyazaki, Japan), which would be converted into compost. Compost originated from leftover food (L) was collected in composting facility in Kumamoto prefecture (Kumamoto, Japan).

\subsection{MPN and Used Antibiotics}

The number of resistant bacteria was estimated by MPN using lactose broth (LB medium Difco, Sparks MD) by adding colistin $\left(25 \mathrm{mg} \cdot \mathrm{L}^{-1}\right)$ (P; polymyxin E), which was not used as therapeutic agent in human nor as animal growth promoter (AGP) in Japan, or chlortetracycline (T) $\left(25 \mathrm{mg} \cdot \mathrm{L}^{-1}\right)$, which was used widely as therapeutic agent in human and veterinary medicine but also used as AGP. For multi drug resistant bacteria (X) the following antimicrobial compounds were co-applied; ciprofloxacin $\left(25 \mathrm{mg} \cdot \mathrm{L}^{-1}\right)$, streptomycin $\left(25 \mathrm{mg} \cdot \mathrm{L}^{-1}\right)$, chloramphenicol $\left(25 \mathrm{mg} \cdot \mathrm{L}^{-1}\right)$, and ampicillin $\left(25 \mathrm{mg} \cdot \mathrm{L}^{-1}\right)$. Serial 10 -fold dilutions $\left(10^{-2}\right.$ to $\left.10^{-5}\right)$ prepared from samples (1g fresh wt.) were inoculated to test vials (5 replicates) including LB medium and the antibiotics. After 5 days 
incubation at $30^{\circ} \mathrm{C}$, bacterial DNA in each vial was extracted as described previously and purified by conventional methods [26] [27].

\subsection{Maintaining the Integrity of the Specifications}

Using the V2 forward primer (41f; 5 'GCTCAGATTGAACGCTGGCG3'), and the V6 reverse primer (1066r; 3 'GTCGAGCACAACACTTTACA5') [29], 16S rDNA of about 1070 bp length was amplified as described previously [30] [31]. Their restriction fragment lengths were measured by microchip electrophoresis systems (Cosmo-i SV1200; Hitachi Electronics Engineering Co., Ltd. Tokyo Japan, or MCE-202 MultiNA; Shimadzu Co., Ltd. Kyoto Japan) after digestion of the PCR product (10 $\mu$ l) using each restriction enzyme, HaeIII or HhaI or Rsa I (10 units, Takara Bio Co. Ltd. Shiga Japan) in buffer solution (10× Low salt buffer, Takara Bio Co. Ltd.) and 5 folds dilution by de-ionized water as described previously [30] [31].

\subsection{Reference Database Used for the Phylogenetic Estimation}

The reference database used for this research included 30,844 post-amplification sequence files for the 41f/ 1066r primers, which were mainly re-edited from small subunit rRNA files in RDP II release 9_61 [32] under 5 bases mismatches in the both in primer annealing sites and were consisted from 1379 bacterial genera, including uncultured and unidentified bacteria.

\subsection{Data Processing for Multi-Template DNA and Phylogenetic Estimation}

As each MPN vials included multi-template DNAs originated from heterogeneous bacteria, the measured MERFL digested from the homogeneous 16S rDNA was selected among the mixed MERFLs digested from the heterogeneous 16S rDNA as described previously [26]. Because all the reference MERFLs were originated from the homogeneous 16S rDNA sequence. The major RFs (represented as $\mathrm{H}$ in Tables 1-3) were those with the highest relative mole concentration (ratio of fluorescent intensity to fragment size). After subtraction of the major RFs from the mixed heterogeneous RFs, the 2nd major RFs were similarly selected (represented as M in Tables 1-3). After subtraction of the 2nd major RFs from the remained heterogeneous RFs, the 3rd major RFs were similarly selected (represented as L in Tables 1-3). The similarity between the measured RFLP (A) and the reference RFLP (B) was calculated as described previously [30] [31] based on the pairwise distance $\left(D_{A B}\right)$ according to Nei and Li [33]. The pairwise distance of the MERFLPs $\left(D_{A B M E}\right)$ was an average of all the $D_{A B s}$ for used restriction enzymes. Similarity $(\%)$ was $\left(1-D_{A B M E}\right) \times 100$ (Tables 1-3). In the phylogenetic estimation, combinations of the 2 restriction enzymes was used when the identical reference MERFL ( $100 \%$ similarity) was not found using all of the measured MERFL for the 3 restriction enzymes. When the identical reference MERFL to the measured MERFL for 2 restriction enzymes was not found, the reference MERFL having the highest similarity (over 80\% ) to the measured MERFL was indicated in most cases (Tables 1-3) [30] [31].

\subsection{Enumeration of Antibiotic Resistant Bacterial Groups by MPN}

By five-tube, three-decimal-dilution experiment, MPNs of each antibiotic resistant bacterial groups $(\mathrm{A} \sim \mathrm{K})$ were estimated (Tables 4-6). Using FDA's Bacterial Analytical Manual [34], confidence limits were obtained and shown in the Tables.

\section{Results}

\subsection{Phylogenetic Estimation of Antibiotic Resistant Bacteria}

Affiliations of 67 MERFLs of colistin resistant bacteria (P) in each MPN vials were summarized in Table 1. All of the 67 MERFLs were divided into 67 OTUs, then ratio of total number of the OTUs to the total number of MERFLs was $100 \%$ (diversity of MERFLs), which was the highest among all the samples analyzed until now [26] [27]. Affiliations of 112 MERFLs of chlortetracycline resistant bacteria (T) in each MPN vials were summarized in Table 2. All of the 112 MERFLs were divided into 88 OTUs, then ratio of total number of the OTUs to the total number of MERFLs was $78.6 \%$, which was lower than that of P. Some Pseudomonas sp. (E) in shochu lee (S) (7 MERFLs) and compost originated from leftover food (L) (8 MERFLs) were placed in the same OUT (Table 2) and some Enterobacteriacea (F) in row cattle feces (R) (8 MERFLs) were placed in the same 
Table 1. Affiliation of colistin resistant bacteria grown in serially diluted LB medium by MERFL ${ }^{\mathrm{a}}$.

\begin{tabular}{|c|c|c|c|c|}
\hline & $\begin{array}{l}\text { Vial } \\
\text { No. }\end{array}$ & $\begin{array}{l}\text { Restriction } \\
\text { enzymes }^{c}\end{array}$ & $\begin{array}{l}\text { Similarity } \\
(\%)^{d}\end{array}$ & Name (Accession number) ${ }^{e}$ \\
\hline \multirow[t]{4}{*}{ A } & $\mathrm{PR}^{-4} 1 \mathrm{M}$ & Ha, R & 83 & Corynebacterium glutamicum (BX9217148, BX927150, BX927152, BX927156) \\
\hline & $\mathrm{PM}^{-4} 4 \mathrm{H}$ & $\mathrm{Ha}, \mathrm{Hh}$ & 92.9 & uncultured Corynebacterium (AM420211) \\
\hline & $\mathrm{PM}^{-5} 1 \mathrm{H}$ & $\mathrm{Ha}, \mathrm{R}, \mathrm{Hh}$ & 88.9 & Nocardiopsis sp. (AF361322) \\
\hline & $\mathrm{PL}^{-2} 1 \mathrm{H}$ & $\mathrm{R}, \mathrm{Hh}$ & 92.9 & Rhodococcus erythropolis (AB177886, AY168580) \\
\hline \multirow[t]{8}{*}{ B } & $\mathrm{PR}^{-3} 3 \mathrm{H}$ & $\mathrm{Ha}, \mathrm{R}, \mathrm{Hh}$ & 95 & Bacillus sp. (AY461745, AY461746, AY461756), B. thuringiensis (AY461762) \\
\hline & $\mathrm{PR}^{-3} 3 \mathrm{M}$ & Ha, Hh & 87.5 & B.oleronius (AF393508) \\
\hline & $\mathrm{PR}^{-3} 5 \mathrm{H}$ & $\mathrm{Ha}, \mathrm{R}, \mathrm{Hh}$ & 95 & Bacillus sp. (AY461742, AY461750) \\
\hline & $\mathrm{PR}^{-5} 1 \mathrm{H}$ & $\mathrm{R}, \mathrm{Hh}$ & 100 & Bacillus sp. (AF326359) \\
\hline & $\mathrm{PM}^{-5} 4 \mathrm{H}$ & Ha, R, Hh & 90.5 & B. oleronius (AY988598, X82492) Exguobacterium sp. (DQ246625) \\
\hline & $\mathrm{PM}^{-5} 3 \mathrm{H}$ & $\mathrm{R}, \mathrm{Hh}$ & 100 & Bacillus sp. (AY461742, AY461750, AJ878858) \\
\hline & $\mathrm{PC}^{-3} 1 \mathrm{M}$ & $\mathrm{Ha}, \mathrm{R}, \mathrm{Hh}$ & 100 & Bacillus sp. (AY566219, AY583458), B. pallidus (Z26930) \\
\hline & $\mathrm{PL}^{-3} 2 \mathrm{M}$ & Ha, R & 83.3 & $\begin{array}{l}\text { B. laevolacticus (B.lvolact3), B. racemilacticus (D16278), Gracilibacillus halotolerans (Grb. } \\
\text { haltol) }\end{array}$ \\
\hline \multirow[t]{17}{*}{$\mathrm{C}$} & $\mathrm{PR}^{-2} 2 \mathrm{M}$ & Ha, Hh & 100 & $\begin{array}{l}\text { Clostridium sp. (AY957603), C. malenominatum (M59099), Anaerococcus hydrogenalis } \\
\text { (D14140), Lactobacillus aviaries (M58808) }\end{array}$ \\
\hline & $\mathrm{PS}^{-4} 5 \mathrm{M}$ & Ha, R & 100 & $\begin{array}{l}\text { C. collagenovorans (C. colgenvo), C. grantii (C. grantii), C. kluyveri (M59092, CP000673), } \\
\text { Anaeroplasma bactoclasticum (M25049) }\left({ }^{f} \mathrm{~J}\right)\end{array}$ \\
\hline & $\mathrm{PL}^{-3} 1 \mathrm{~L}$ & Ha, Hh & 100 & C.butyricum (M59085), Ureaplasma diversum (D78650), U. canigenitalium (D78648) \\
\hline & $\mathrm{PR}^{-3} 4 \mathrm{H}$ & Ha, R, Hh & 86 & Alicyclobacillus hesperidum (AB059678, AB059679), A. sacchari (AB262020) \\
\hline & $\mathrm{PR}^{-2} 3 \mathrm{H}$ & Ha, Hh & 100 & $\begin{array}{l}\text { A. pomorum (AB089840), Streptococcus mutans (AF139601), Enterococcus faecalis } \\
\text { (AY94256) }\end{array}$ \\
\hline & $\mathrm{PR}^{-2} 2 \mathrm{H}$ & Ha, R & 100 & Syntrophomonas wolfei (СР000448) \\
\hline & $\mathrm{PL}^{-2} 4 \mathrm{H}$ & Ha, R & 100 & S. erecta (DQ86234), S. sporosyntrop (DQ112186) \\
\hline & $\mathrm{PR}^{-2} 4 \mathrm{~L}$ & $\mathrm{Ha}, \mathrm{Hh}$ & 100 & Paenibacillus peoriae (D78476), Bacillus brevis (X60612), B. edaphicus (AB045093) \\
\hline & $\mathrm{PL}^{-3} 3 \mathrm{~L}$ & Ha, R, Hh & 82.2 & P. lautus (D85394, D85609) \\
\hline & $\mathrm{PM}^{-4} 3 \mathrm{~L}$ & Ha, Hh & 85.6 & Ruminococcus albus (AY445592), \\
\hline & $\mathrm{PL}^{-4} 4 \mathrm{M}$ & Ha, R & 100 & R. productus (AY937379), Bacillus edaphicus (B. edaphicu) $\left({ }^{\mathrm{f}} \mathrm{B}\right)$ \\
\hline & $\mathrm{PR}^{-2} 1 \mathrm{H}$ & Ha, R, Hh & 85.6 & Desulfotomaculum nigrificans (AB026550) \\
\hline & $\mathrm{PR}^{-2} 4 \mathrm{M}$ & Ha, R, Hh & 93.3 & Desulfosporosinus orientis (Ds.orient2) \\
\hline & $\mathrm{PR}^{-4} 5 \mathrm{H}$ & $\mathrm{R}, \mathrm{Hh}$ & 100 & Leuconostoc gelidum (AB004661) \\
\hline & $\mathrm{PM}^{-4} 4 \mathrm{~L}$ & Ha, R & 100 & $\begin{array}{l}\text { Lactobacillus vaccinostercus (AB218801), L. bifermentans (M58809), L. coryniformis } \\
\text { (M58813) }\end{array}$ \\
\hline & $\mathrm{PR}^{-3} 2 \mathrm{H}$ & Ha, R, Hh & 100 & $\begin{array}{l}\text { Slenomonas ruminantium (AB198430, AB198432, AB198433, AB198438), Megamonas } \\
\text { hypermegale (AJ420107) }\end{array}$ \\
\hline & $\mathrm{PL}^{-3} 1 \mathrm{H}^{\mathrm{g}}$ & Ha, R & 100 & Staphylococcus aureus (СР000730), S. cohnii (Stp.cohni3) \\
\hline \multirow[t]{9}{*}{$\mathrm{D}$} & $\mathrm{PR}^{-4} 1 \mathrm{H}$ & Ha, R & 100 & Sphingomonas sp. (Y12803) \\
\hline & $\mathrm{PL}^{-3} 1 \mathrm{H}^{\mathrm{g}}$ & $\mathrm{R}, \mathrm{Hh}$ & 100 & S. mali (Y09638), S. pruni (Y09637), S. asaccharolyticas (Y09639) \\
\hline & $\mathrm{PR}^{-5} 4 \mathrm{H}$ & $\mathrm{R}, \mathrm{Hh}$ & 94.4 & $\begin{array}{l}\text { Methylobacrerium sp. (Mlb.sp.PK1, Mlb.sp.PR6), Methylosporovibrio methanica } \\
\text { (Mls.methan) }\end{array}$ \\
\hline & $\mathrm{PM}^{-5} 2 \mathrm{H}$ & Ha, R, Hh & 84 & Orientia tsutsugamuchi (AM494475) \\
\hline & $\mathrm{PM}^{-4} 3 \mathrm{H}$ & Ha, R & 100 & Acidosphaera rubrifaciens (D86512), Erythrobacter longus (Erb. longus) \\
\hline & $\mathrm{PL}^{-4} 4 \mathrm{H}$ & Ha, R, Hh & 93.3 & Rhodopseudomonas acidophilas (M34128) \\
\hline & $\mathrm{PR}^{-2} 1 \mathrm{M}$ & Ha, R, Hh & 86.7 & uncultured beta proteobacterium (AB294945) \\
\hline & $\mathrm{PS}^{-4} 5 \mathrm{~L}$ & Ha, Hh & 83.3 & Telluria mixta (X65589) \\
\hline & $\mathrm{PL}^{-3} 2 \mathrm{H}$ & $\mathrm{Ha}, \mathrm{R}, \mathrm{Hh}$ & 93.3 & Ralstonia solanacearum (AY642432) \\
\hline
\end{tabular}




\section{Continued}

\begin{tabular}{|c|c|c|c|c|}
\hline \multirow[t]{5}{*}{$\mathrm{E}$} & $\mathrm{PR}^{-3} 4 \mathrm{M}$ & Ha, $\mathrm{Hh}$ & 83.3 & Pseudomonas sp. (DQ279343), P. stutzeri (U26262), \\
\hline & $\mathrm{PR}^{-5} 5 \mathrm{H}$ & Ha, R, Hh & 86.9 & Pseudomonas sp. (AM410901), Hahella chejuensis (CР000155) \\
\hline & $\mathrm{PS}^{-4} 4 \mathrm{H}$ & Ha, R, Hh & 91.7 & Pseudomonas sp. (AM111028) \\
\hline & $\mathrm{PS}^{-4} 5 \mathrm{H}$ & Ha, R & 100 & P. putida (DQ232745) \\
\hline & $\mathrm{PL}^{-3} 3 \mathrm{M}$ & $\mathrm{Ha}, \mathrm{R}, \mathrm{Hh}$ & 94.8 & P. caricapapayae (D84010) \\
\hline \multirow[t]{2}{*}{$\mathrm{F}$} & $\mathrm{PR}^{-4} 4 \mathrm{H}$ & Ha, R, Hh & 85 & Vibrio sp. (DQ173039), Methylobacillus flagellates (CP000284) \\
\hline & $\mathrm{PM}^{-4} 3 \mathrm{M}$ & $\mathrm{R}, \mathrm{Hh}$ & 100 & Vibrio sp. (DQ146975), V. harveyi (AY911396,AY911387), V. carchariae (X74693), \\
\hline \multirow[t]{6}{*}{ G } & $\mathrm{PR}^{-3} 2 \mathrm{M}$ & Ha, Hh & 100 & Xenorhabdus indica (AM040494) \\
\hline & $\mathrm{PR}^{-5} 2 \mathrm{H}$ & Ha, R & 93 & $\begin{array}{l}\text { Photobacterium profundum (CR378665, CR378680), Thermoanaebacterium therm (Tbm. thslf) } \\
\left({ }^{f} \mathrm{C}\right) \text {, Eubacterium yurii (Eub. yurii) }\left({ }^{\mathrm{f}} \mathrm{C}\right) .\end{array}$ \\
\hline & $\mathrm{PR}^{-5} 3 \mathrm{H}$ & $\mathrm{R}, \mathrm{Hh}$ & 92.9 & uncultured gamma proteobacteria (AF445671) \\
\hline & $\mathrm{PM}^{-4} 4 \mathrm{M}$ & Ha, R & 100 & $\begin{array}{l}\text { Marinobacter sp. (AB089803), Pseudomonas sp. (AM110949), Sporolactobacillus } \\
\left.\text { laevis (D16287) ( }{ }^{(} \mathrm{C}\right)\end{array}$ \\
\hline & $\mathrm{PL}^{-3} 5 \mathrm{M}$ & $\mathrm{Ha}, \mathrm{R}, \mathrm{Hh}$ & 88.9 & Nitrococcus mobilis (L35510,) \\
\hline & $\mathrm{PL}^{-2} 4 \mathrm{M}$ & Ha, R & 100 & Nitrococcus mobilis (Nc. mobilis), Legionella hackeliae (Leg. hackel) \\
\hline \multirow[t]{6}{*}{$\mathrm{H}$} & $\mathrm{PM}^{-5} 1 \mathrm{M}$ & Ha, Hh & 100 & Desulfovibrio marrakechensis (AM947130) \\
\hline & $\mathrm{PL}^{-3} 3 \mathrm{H}$ & Ha, R, Hh & 91.7 & uncultured delta proteobacteria (AY771945) \\
\hline & $\mathrm{PL}^{-3} 4 \mathrm{H}$ & Ha, R, Hh & 90.5 & Desulfobacterium sp. (DQ146482) \\
\hline & $\mathrm{PL}^{-3} 5 \mathrm{H}$ & Ha, R, Hh & 85.7 & Stigmatella erecta (AJ233933), S. aurantiaca (AJ233936, AJ233937) \\
\hline & $\mathrm{PL}^{-3} 5 \mathrm{~L}$ & Ha, R & 92.9 & Desulfomonile tiedjei (M26635) \\
\hline & $\mathrm{PL}^{-2} 1 \mathrm{M}$ & Ha, R & 100 & Corallococcus coralloides (AY072739) \\
\hline \multirow[t]{3}{*}{$\mathrm{J}$} & $\mathrm{PR}^{-3} 1 \mathrm{H}$ & $\mathrm{R}, \mathrm{Hh}$ & 100 & uncultured Gemmatimonadetes (AY9211783, AY921939, AY921994, AY922110) \\
\hline & $\mathrm{PM}^{-4} 1 \mathrm{H}$ & $\mathrm{Ha}, \mathrm{R}, \mathrm{Hh}$ & 90.5 & uncultured Acidobacteria bacterium (AY922163) \\
\hline & $\mathrm{PL}^{-3} 4 \mathrm{M}$ & Ha, R, Hh & 84.1 & Deinococcus murrayi (Y13042) \\
\hline \multirow[t]{8}{*}{ K } & $\mathrm{PR}^{-2} 4 \mathrm{H}$ & Ha, R, Hh & 93.3 & uncultured rumen bacterium (AB034009, AB185580) \\
\hline & $\mathrm{PR}^{-3} 5 \mathrm{M}$ & $\mathrm{Ha}, \mathrm{Hh}$ & 100 & uncultured bacterium (AB240503) \\
\hline & $\mathrm{PM}^{-5} 3 \mathrm{M}$ & $\mathrm{R}, \mathrm{Hh}$ & 83.3 & uncultured bacterium (AY854278) \\
\hline & $\mathrm{PM}^{-5} 4 \mathrm{M}$ & Ha, Hh & 92.9 & uncultured bacterium (AY768822, DQ251791) \\
\hline & $\mathrm{PS}^{-4} 4 \mathrm{M}$ & $\mathrm{R}, \mathrm{Hh}$ & 100 & halophilic bacterium(AB042504) \\
\hline & $\mathrm{PR}^{-2} 3 \mathrm{M}$ & $\mathrm{R}, \mathrm{Hh}$ & 83.3 & Adiantum pedatum (AF244549) \\
\hline & $\mathrm{PM}^{-4} 2 \mathrm{M}$ & Ha, R & 94.4 & Olavius loisae endosymbiont (AF104475) \\
\hline & $\mathrm{PM}^{-4} 2 \mathrm{~L}$ & Ha, R & 90 & marine psychrophile IC079 (U85854) \\
\hline
\end{tabular}

${ }^{\mathrm{a}}$ Grouping was based on affiliation by MERFL; Actinobacteria (A), Bacillus spp. (B), the other Firmicutes (C), $\alpha$, $\beta$-Proteobacteria (D), Pseudomonas sp. (E), Enterobacteriacea (F), the other $\gamma$-Proteobacteria (GG), $\delta, \varepsilon$-Proteobacteria (H), Cytophaga (I), the other bacteria (J), and unidentified or uncultured bacterial group (K). ${ }^{b}$ The $1^{\text {st }}$ letter in vial indicates used antibiotics; "P" stands for colistin (polymyxin E). The 2nd letter in vial indicates samples; "R" stands for row cattle feces, "M" stands for cattle feces manure, "S" stands for shochu lee, and "L" stands for compost originated from leftover food. Exponential of vial number represents the decimal dilution of the vial. The 2nd number of vial number (1 - 5) represents number in 5 replicates for the each decimal dilution. "H" of last letter represents MERFL originating from the major 16S rDNA, "M" represents from the 2nd major 16S rDNA, and "L" represents from the 3rd major $16 \mathrm{~S}$ rDNA. ${ }^{~}$ Restriction enzymes used for similarity search; "Ha", "R", and "Hh" stand for Hae III, Rsa I, and Hha I. For the measured MERFLP which had no completely identical theoretical MERFLP, the theoretical MERFLP having the highest similarity using all the RFLPs was presented with the similarity as described in the materials and method. ${ }^{\mathrm{d}}$ The similarity between the measured RFLP

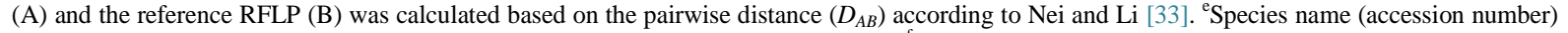
of the theoretical MERFL having the highest similarity with the measured MERFL. ${ }^{T}$ The theoretical MERFL (accession number) having the same MERFL belonged to different group in parenthesis. ${ }^{\mathrm{g}}$ The MERFL falling into different groups by using the different restriction enzymes. 
Table 2. Affiliation of chlortetracycline resistant bacteria grown in serially diluted LB medium by MERFL ${ }^{\mathrm{a}}$.

\begin{tabular}{|c|c|c|c|c|}
\hline & $\begin{array}{l}\text { Vial } \\
\text { No. }\end{array}$ & $\begin{array}{l}\text { Restriction } \\
\text { enzymes }^{c}\end{array}$ & $\begin{array}{l}\text { Similarity } \\
(\%)^{d}\end{array}$ & Name (Accession number) $)^{\mathrm{e}}$ \\
\hline \multirow[t]{10}{*}{ A } & $\mathrm{TM}^{-3} 2 \mathrm{M}$ & R, Hh & 90 & Streptomyces sp. (DQ250003), S. filamentosus (DQ026632), S. bikiniensis (Stm. bikini) \\
\hline & $\mathrm{TR}^{-4} 1 \mathrm{M}$ & $\mathrm{R}, \mathrm{Hh}$ & 100 & $\begin{array}{l}\text { Streptomyces sp. (U93336, U93338), Streptoverticillium baldaccii (X53164), S. abikoense } \\
\text { (X53168) }\end{array}$ \\
\hline & $\mathrm{TM}^{-5} 1 \mathrm{H}^{\mathrm{g}}$ & Ha, R & 100 & $\begin{array}{l}\text { Microbacterium flavescens (Mbm. Flaves), M. hominis (Mbm. homini), Stomatococcus } \\
\text { mucilaginosus (Stt. muclag) }\left({ }^{\mathrm{f}} \mathrm{F}\right)\end{array}$ \\
\hline & $\mathrm{TM}^{-5} 3 \mathrm{H}$ & Ha, Hh & 100 & Gordonia defluvii (AY650267) \\
\hline & $\mathrm{TM}^{-4} 1 \mathrm{M}$ & Ha, $\mathrm{R}$ & 100 & uncultured actinobacterium (AY792227) \\
\hline & $\mathrm{TR}^{-2} 1 \mathrm{H}$ & $\mathrm{Ha}, \mathrm{R}, \mathrm{Hh}$ & 95.2 & uncultured actinobacterium (AY792228) \\
\hline & $\mathrm{TM}^{-3} 1 \mathrm{~L}^{\mathrm{g}}$ & Ha, Hh & 83.3 & $\begin{array}{l}\text { Bifidobacterium sp. (AF321296), B. subtile (D89378, D89379), B. gallicum (D86189), } \\
\text { B.magnum (D86193) }\end{array}$ \\
\hline & $\mathrm{TS}^{-3} 1 \mathrm{~L}$ & $\mathrm{R}, \mathrm{Hh}$ & 100 & Kutzneria kofuensis (AF114801) \\
\hline & $\mathrm{TS}^{-3} 2 \mathrm{H}$ & $\mathrm{R}, \mathrm{Hh}$ & 100 & Propionibacteriacease bacterium (AB298731), Mycobacteriaceae bacterim (AB298730) \\
\hline & $\mathrm{TL}^{-3} 4 \mathrm{H}$ & $\mathrm{R}, \mathrm{Hh}$ & 92.9 & $\begin{array}{l}\text { Streptacidiphilus neutrinimicu (AF074409), Lactobacillus catenaformis (L. catenofo) }\left({ }^{\mathrm{f}} \mathrm{F}\right) \text {, } \\
\text { Geodermatophilus sp. (X92358, X92361) }\end{array}$ \\
\hline \multirow[t]{9}{*}{ B } & $\mathrm{TM}^{-4} 5 \mathrm{H}$ & Ha, R, Hh & 100 & Bacillus funiculus (AB271136), B. cereus (CP000764, AY920248, DQ207729, DQ209210), \\
\hline & $\mathrm{TM}^{-3} 1 \mathrm{H}$ & Ha, R, Hh & 100 & $\begin{array}{l}\text { B. cereus (AY920248, DQ207729, DQ209210), B. mycoides (B. mycoides), } \\
\text { B. weihenstephanensis (CP000903) }\end{array}$ \\
\hline & $\mathrm{TM}^{-3} 5 \mathrm{~L}$ & Ha, R & 100 & B. anthracis (X55059) \\
\hline & $\mathrm{TM}^{-4} 2 \mathrm{M}$ & $\mathrm{R}, \mathrm{Hh}$ & 92.9 & B. cohnii (DQ166855) \\
\hline & $\mathrm{TM}^{-3} 2 \mathrm{H}$ & Ha, R & 100 & $\begin{array}{l}\text { B. sphaericus (L14010, L14011, L14012), B. pumilus (DQ275671), Clostridium botulinum } \\
\text { (CP000726) }\left({ }^{\mathrm{f}} \mathrm{C}\right)\end{array}$ \\
\hline & $\mathrm{TM}^{-3} 4 \mathrm{M}$ & $\mathrm{Ha}, \mathrm{R}, \mathrm{Hh}$ & 88.6 & B. badius (AB098575) \\
\hline & $\mathrm{TS}^{-5} 3 \mathrm{~L}$ & $\mathrm{R}, \mathrm{Hh}$ & 90 & B. pantothenticus (D16275), Virgibacillus marismortui (DQ010162), B. olivae (Dq139839) \\
\hline & $\mathrm{TL}^{-4} 3 \mathrm{M}$ & $\mathrm{Ha}, \mathrm{Hh}$ & 83.3 & B. edaphicus (AB045093, AF006076), B. brevis (X60612) \\
\hline & $\mathrm{TL}^{-4} 3 \mathrm{~L}$ & Ha, R, Hh & 85.7 & B. vortex (AM039409) \\
\hline \multirow[t]{19}{*}{$\mathrm{C}$} & $\begin{array}{l}\mathrm{TS}^{-3} 2 \mathrm{M} \\
\mathrm{TL}^{-4} 2 \mathrm{M}\end{array}$ & $\begin{array}{l}\text { Ha, R } \\
\text { Ha, R }\end{array}$ & $\begin{array}{l}100 \\
92.9\end{array}$ & $\begin{array}{l}\text { Clostridium collagenovorans (C. colgenvo), C. kluyveri (CP000673, M59092), C. grantii } \\
\text { (C. grantii), Mycoplasma meleagridis (L24106), M. fermentans (M. fermenta), Acholoep- } \\
\text { lasma modicum (Acp. modicu) }\end{array}$ \\
\hline & $\mathrm{TS}^{-4} 3 \mathrm{M}$ & $\mathrm{Ha}, \mathrm{Hh}$ & 92.9 & P. terrigena $(\mathrm{AB} 248087)$ \\
\hline & $\mathrm{TL}^{-5} 1 \mathrm{M}$ & Ha, R & 100 & $\begin{array}{l}\text { P. thiaminolyticus (D88513), P. alvei (Pae. alvei, Pae. alvei3), P. azotofixans (Pae. azofi2), } \\
\text { Staphylococcus capitis (L37599) }\end{array}$ \\
\hline & $\mathrm{TL}^{-5} 3 \mathrm{~L}$ & $\mathrm{Ha}, \mathrm{Hh}$ & 83.3 & $\begin{array}{l}\text { P. lautus (D85609, D85394), Clostridium proteoclasticum (U37378), Leuconostoc fallax } \\
\text { (Lc. fallax), Mycoplasms penetrans (BA000026) }\left({ }^{\mathrm{f}} \mathrm{I}\right)\end{array}$ \\
\hline & $\mathrm{TS}^{-5} 1 \mathrm{H}$ & Ha, R, Hh & 91.7 & Panibacillus sp (AB043866, AB23867, AB43869), P. campinasensis (DQ232773), \\
\hline & $\mathrm{TR}^{-5} 4 \mathrm{~L}$ & $\mathrm{R}, \mathrm{Hh}$ & 100 & Lactobacillus fermentum (AF522394), \\
\hline & $\mathrm{TR}^{-5} 5 \mathrm{H}$ & Ha, R & 100 & L. plantarum (DQ239695, DQ239699), L. casei (L. casei1), L. mali (M58824) \\
\hline & $\mathrm{TS}^{-4} 3 \mathrm{H}$ & $\mathrm{R}, \mathrm{Hh}$ & 100 & $\begin{array}{l}\text { L. sanfranciscensis (L. sanfranc), Vagococcus salmoninarum (Vag. salmon), Brevibacte- } \\
\text { rium incertum (Y14650) }\left({ }^{\mathrm{f}} \mathrm{A}\right)\end{array}$ \\
\hline & $\mathrm{TL}^{-3} 1 \mathrm{H}$ & $\mathrm{R}, \mathrm{Hh}$ & 100 & L. delbrueckii (CR954253) \\
\hline & $\mathrm{TR}^{-3} 1 \mathrm{M}$ & Ha, R, Hh & 100 & $\begin{array}{l}\text { Eubacterium sp. (AF385552), E. subrreum-like (AF2887776), Streoptococcus constellatus } \\
\text { (Stc.const3) }\end{array}$ \\
\hline & $\mathrm{TS}^{-3} 2 \mathrm{~L}$ & Ha, R & 82.9 & E.cylindroides (AB018186) \\
\hline & $\mathrm{TM}^{-4} 3 \mathrm{H}$ & Ha, R, Hh & 93.3 & Streptococcus sp. (AF084833) \\
\hline & $\mathrm{TM}^{-4} 4 \mathrm{H}$ & Ha, R, Hh & 91.7 & Pullulanibacillus naganoensis (AB021193), P. mentitum (AM931441) \\
\hline & $\mathrm{TR}^{-2} 1 \mathrm{M}$ & $\mathrm{R}, \mathrm{Hh}$ & 92.9 & Thermoanaerobacter celluloly (Tab. cllul, Tab. cellu2) \\
\hline & $\mathrm{TS}^{-5} 1 \mathrm{~L}$ & $\mathrm{Ha}, \mathrm{Hh}$ & 92.9 & Facalibacterium prausnitzii (AJ270469), Selenomonas sputigena (Slm. sputig) \\
\hline & $\mathrm{TS}^{-4} 1 \mathrm{~L}$ & $\mathrm{Ha}, \mathrm{Hh}$ & 100 & Pediocuccus urinaeequi (D87677) \\
\hline & $\mathrm{TS}^{-4} 2 \mathrm{M}$ & $\mathrm{R}, \mathrm{Hh}$ & 100 & Desulfosporosinus orientis (Ds.orient2) \\
\hline & $\mathrm{TS}^{-3} 4 \mathrm{M}$ & $\mathrm{R}, \mathrm{Hh}$ & 92.9 & Desulfotomaculum luciae (AF069293) \\
\hline & $\mathrm{TS}^{-3} 5 \mathrm{~L}$ & $\mathrm{R}, \mathrm{Hh}$ & 90 & Sporohalobacter lortetii (M59122) \\
\hline
\end{tabular}




\section{Continued}

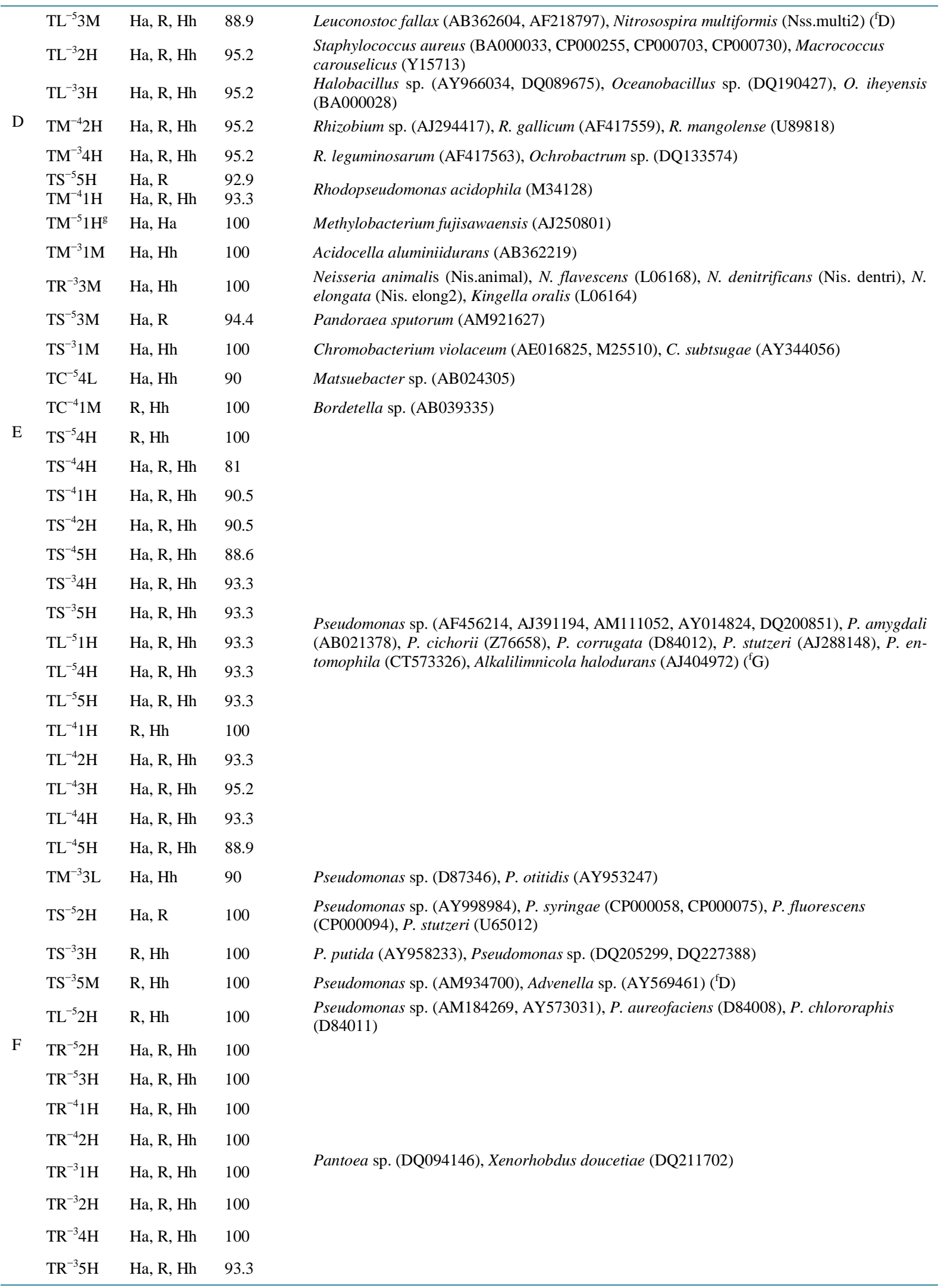




\section{Continued}

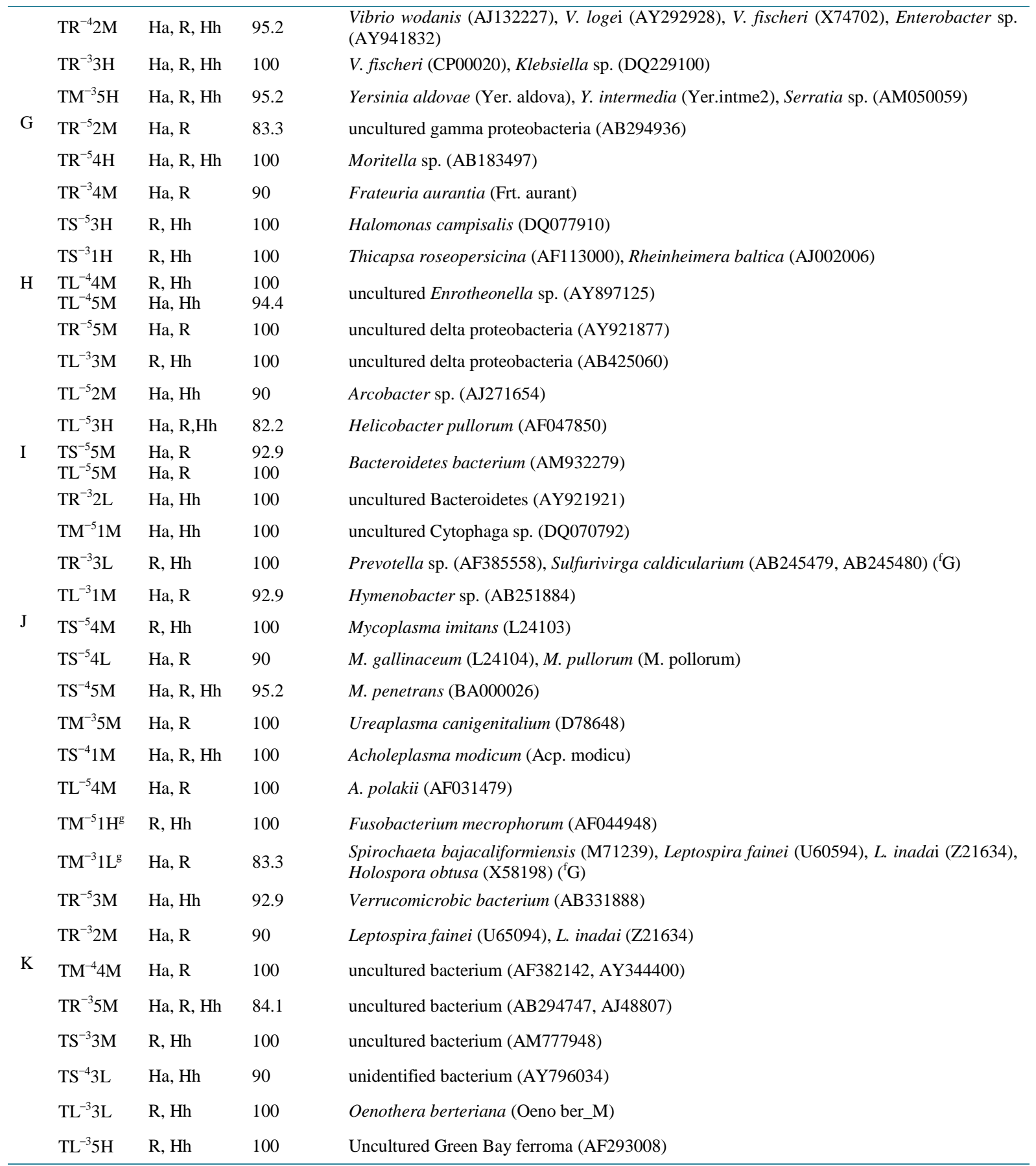

${ }^{\mathrm{a}}$ Grouping was based on affiliation by MERFL; Actinobacteria (A), Bacillus spp. (B), the other Firmicutes (C), $\alpha, \beta$-Proteobacteria (D), Pseudomonas sp. (E), Enterobacteriacea (F), the other $\gamma$-Proteobacteria (GG), $\delta$, $\varepsilon$-Proteobacteria (H), Cytophaga (I), the other bacteria (J), and unidentified or uncultured bacterial group (K). 'The $1^{\text {st }}$ letter in vial indicates used antibiotics; “T” stands for chlortetracycline. The 2nd letter in vial indicates samples; "R" stands for row cattle feces, "M" stands for cattle feces manure, "S" stands for shochu lee, and "L" stands for compost originated from leftover food. Exponential of vial number represents the decimal dilution of the vial. The 2nd number of vial number (1 - 5) represents number in 5 replicates for the each decimal dilution. "H" of last letter represents MERFL originating from the major 16S rDNA, "M" represents from the 2nd major 16S rDNA, and "L” represents from the 3rd major 16S rDNA. 'Restriction enzymes used for similarity search; "Ha”, "R", and "Hh" stand for Hae III, Rsa I, and Hha I. For the measured MERFLP which had no completely identical theoretical MERFLP, the theoretical MERFLP having the highest similarity using all the RFLPs was presented with the similarity as described in the materials and method. ${ }^{\mathrm{d}}$ The similarity between the measured RFLP (A)

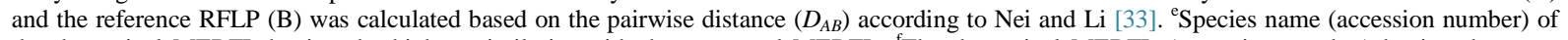
the theoretical MERFL having the highest similarity with the measured MERFL. ${ }^{\mathrm{f}}$ The theoretical MERFL (accession number) having the same MERFL belonged to different group in parenthesis. ${ }^{\text {g}}$ The MERFL falling into different groups by using the different restriction enzymes. 
Table 3. Affiliation of multi drug resistant bacteria grown in serially diluted LB medium by MERFL ${ }^{\mathrm{a}}$.

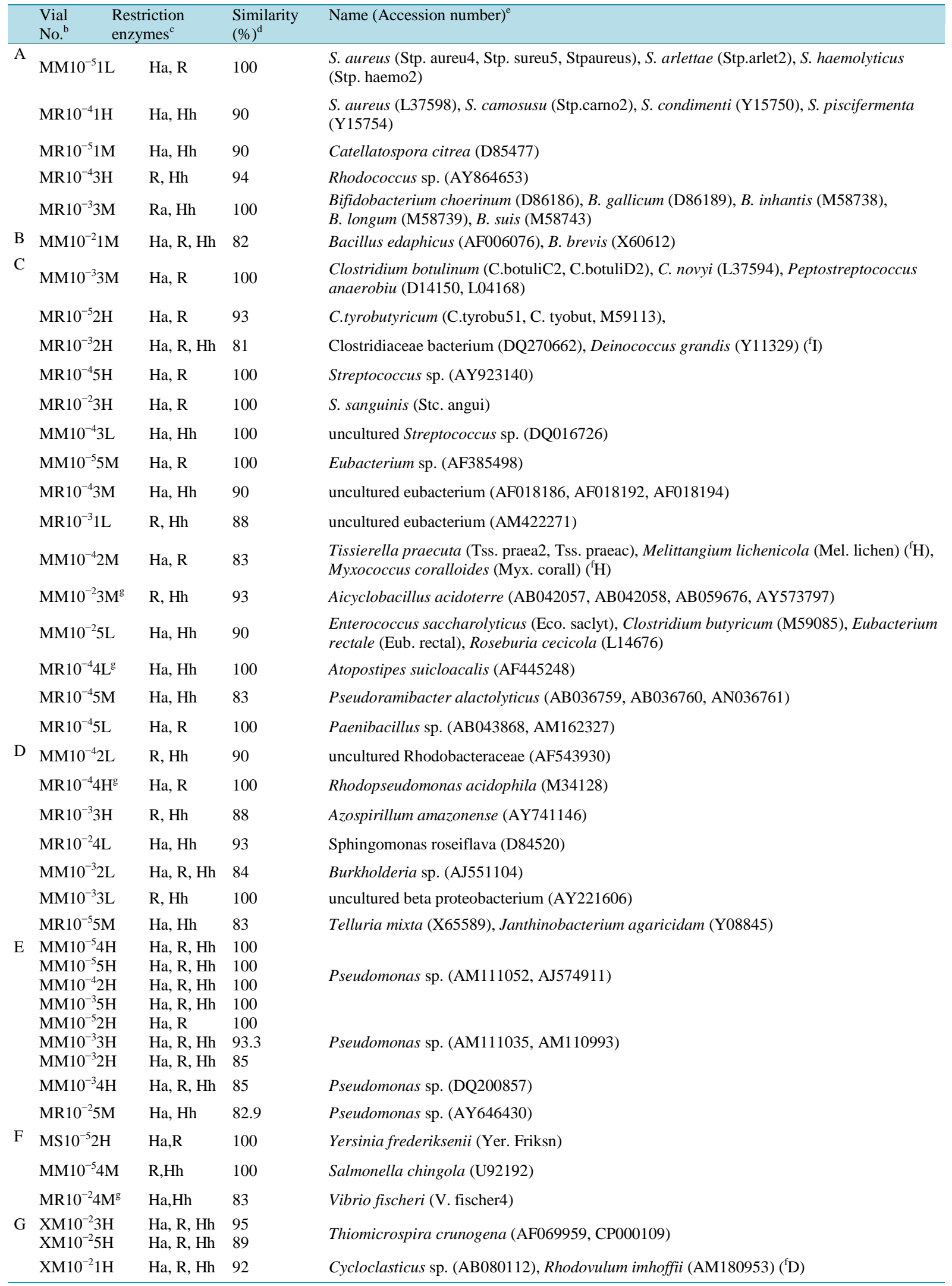




\section{Continued}

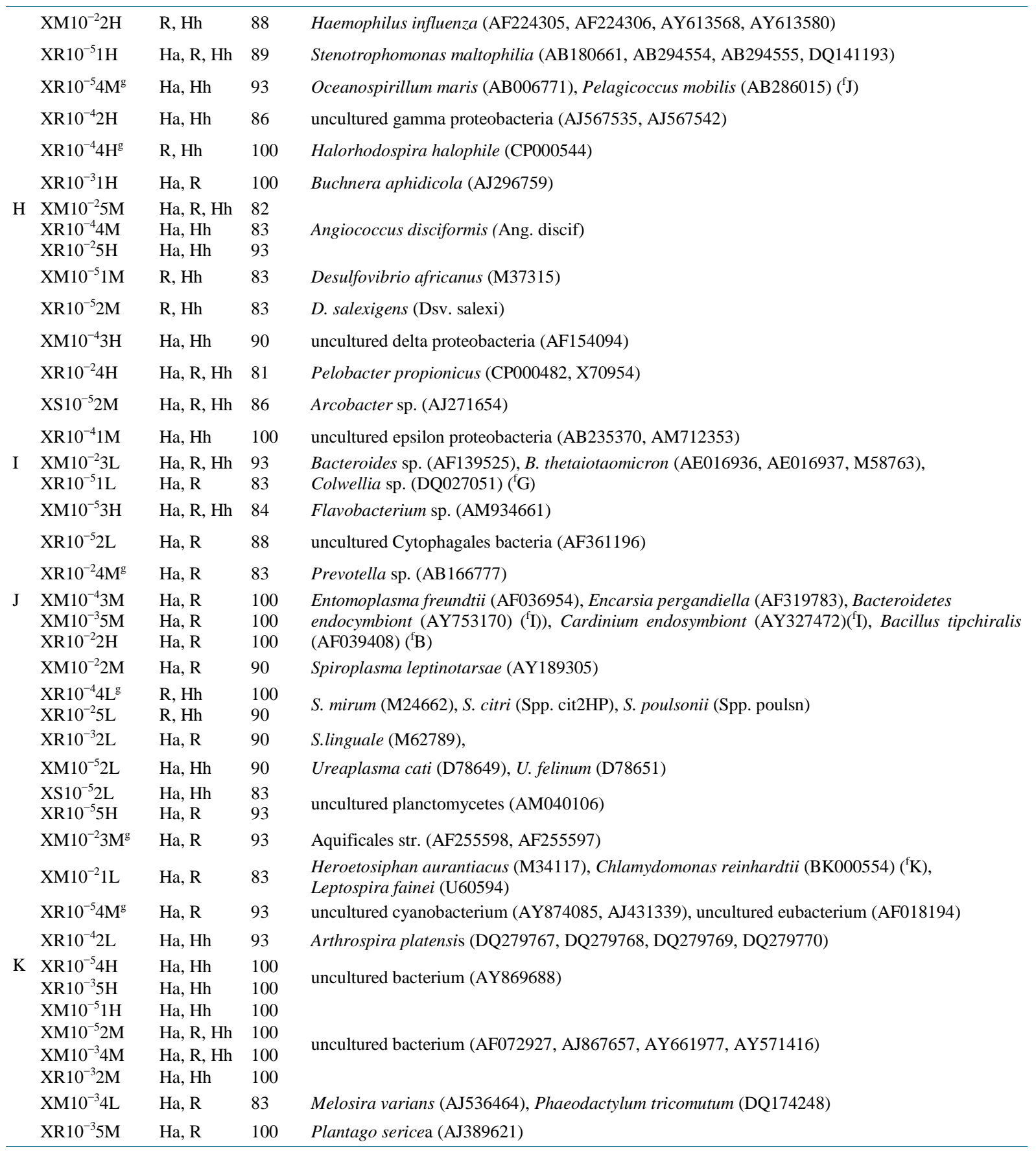

${ }^{\mathrm{a} G}$ Grouping was based on affiliation by MERFL; Actinobacteria (A), Bacillus spp. (B), the other Firmicutes (C), $\alpha$, $\beta$-Proteobacteria (D), Pseudomonas sp. (E), Enterobacteriacea (F), the other $\gamma$-Proteobacteria (GG), $\delta$, $\varepsilon$-Proteobacteria (H), Cytophaga (I), the other bacteria (J), and unidentified or uncultured bacterial group (K). ${ }^{\circ}$ The $1^{\text {st }}$ letter in vial indicates used antibiotics; " $\mathrm{X}$ " stands for multi drugs, ciprofloxacin, streptomycin, chloramphenicol, and ampicillin. The 2nd letter in vial indicates samples; "R" stands for row cattle feces, "M" stands for cattle feces manure, "S" stands for shochu lee, and "L" stands for compost originated from leftover food. Exponential of vial number represents the decimal dilution of the vial. The 2nd number of vial number $(1-5)$ represents number in 5 replicates for the each decimal dilution. " $H$ " of last letter represents MERFL originating from the major 16S rDNA, "M" represents from the 2nd major 16S rDNA, and "L" represents from the 3rd major 16S rDNA. "Restriction enzymes used for similarity search; "Ha", "R", and "Hh" stand for Hae III, Rsa I, and Hha I. For the measured MERFLP which had no completely identical theoretical MERFLP, the theoretical MERFLP having the highest similarity using all the RFLPs was presented with the similarity as described in the materials and method. ${ }^{\mathrm{d}}$ The similarity between the measured RFLP (A) and the reference RFLP (B) was calculated based on the pairwise distance $\left(D_{A B}\right)$ according to Nei and Li [33]. ${ }^{~}$ Species name (accession number) of the theoretical MERFL having the highest similarity with the measured MERFL. ${ }^{\mathrm{f}}$ The theoretical MERFL (accession number) having the same MERFL belonged to different group in parenthesis. ${ }^{\mathrm{g}}$ The MERFL falling into different groups by using the different restriction enzyme. 


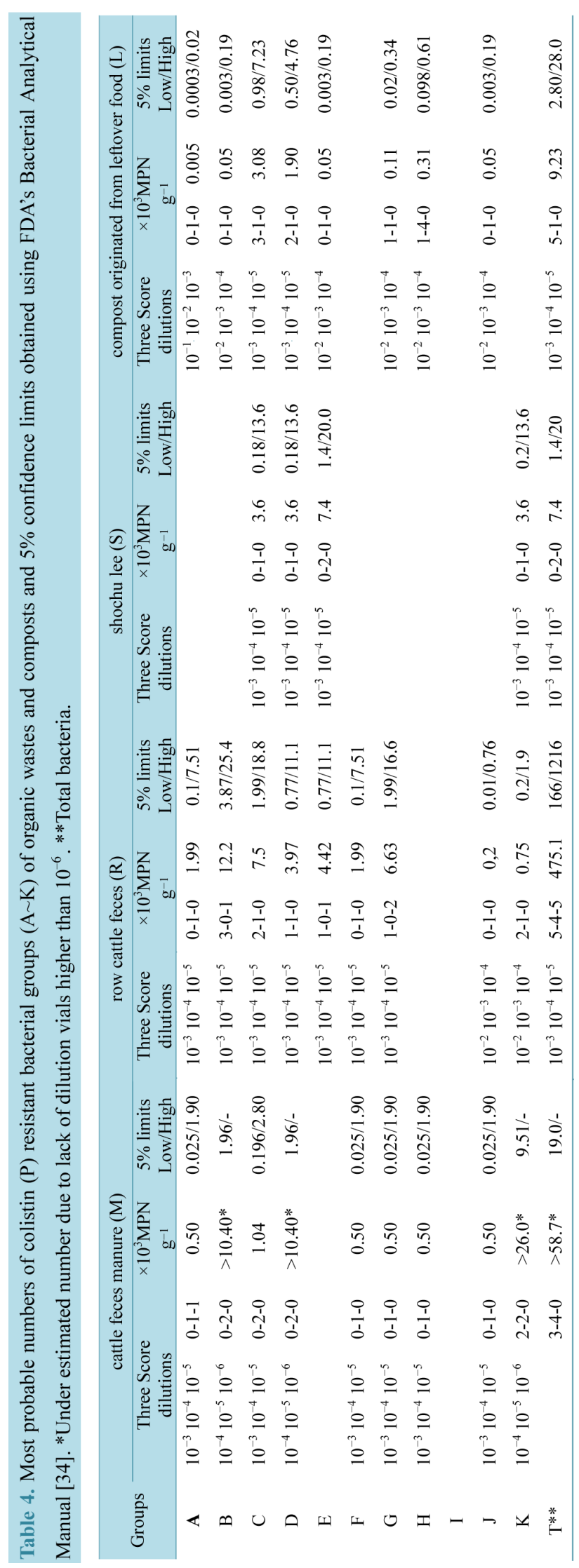




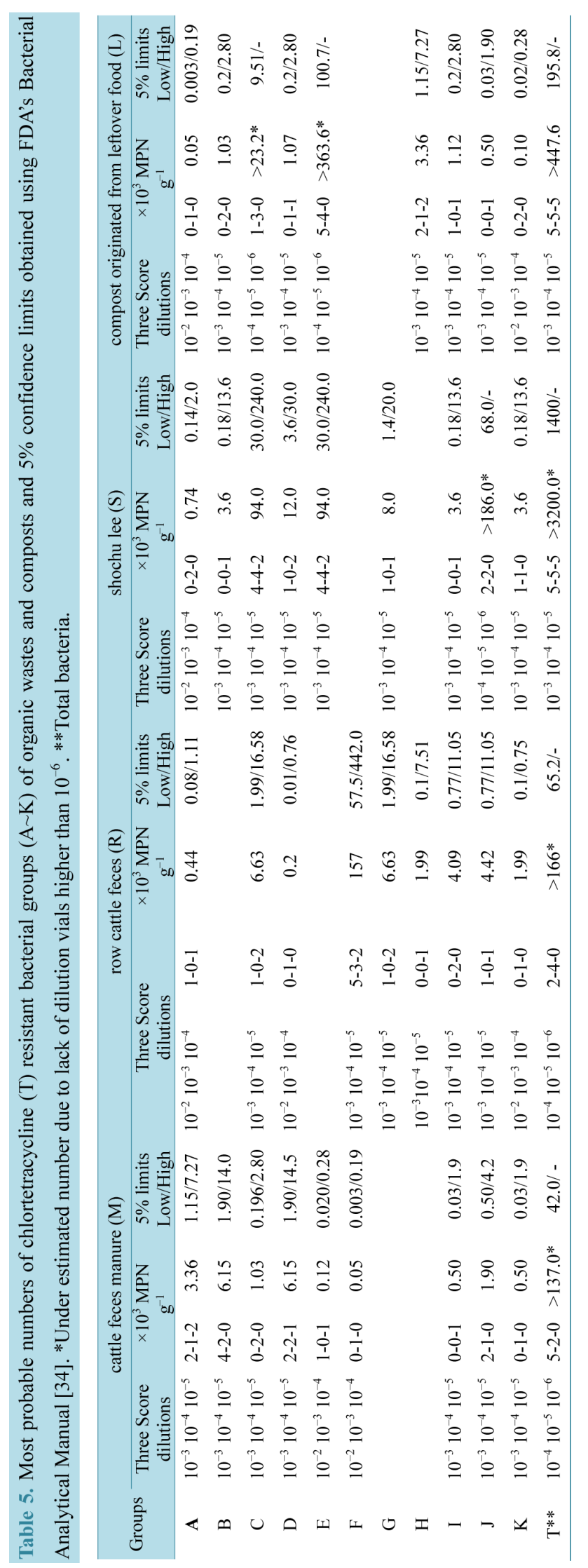




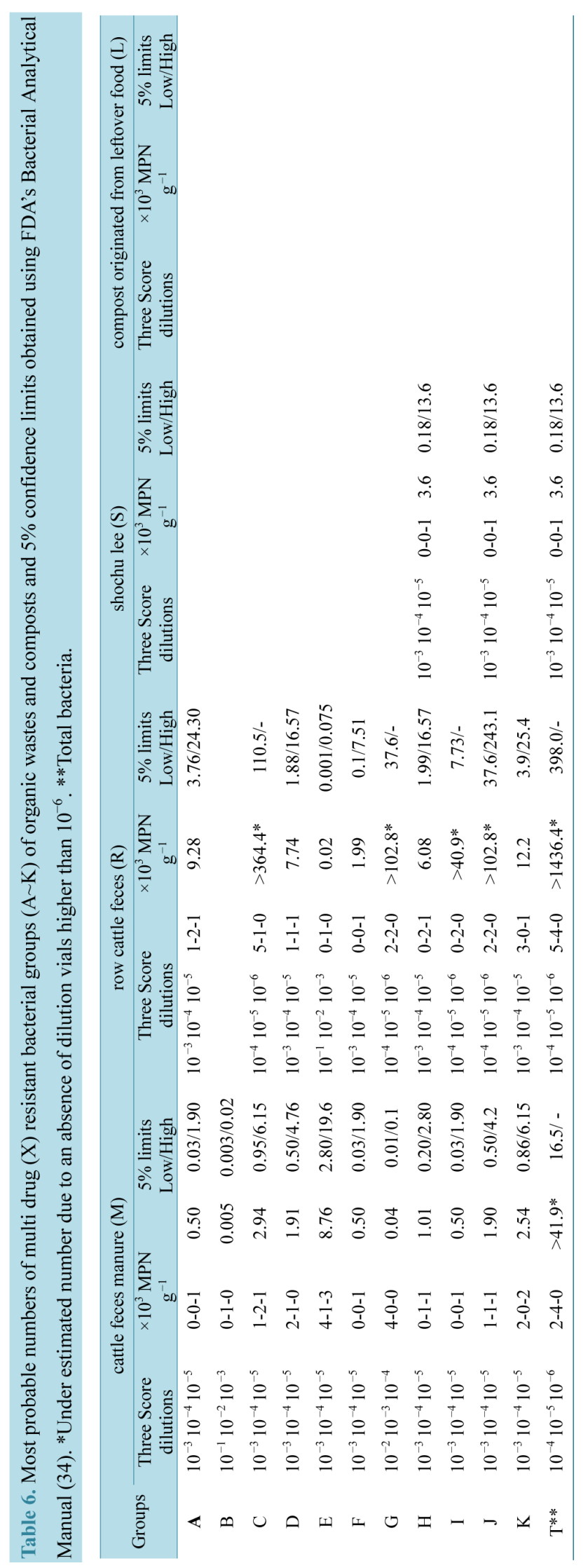


OUT (Table 2), which lowered the diversity of the MERFLs. Affiliations of 80 MERFLs of multi drug resistant bacteria (X) in each MPN vials were summarized in Table 3. All of the 80 MERFLs were divided into 62 OTUs, then ratio of total number of the OTUs to the total number of MERFLs was 77.5\%, which was also lower than that of P (Table 3). Some MERFLs of the group E, group G, group H, group I, group J, and group $\mathrm{K}$ were placed in the same OUTs (Table 3).

The precisions of the affiliations of each MERFLs were lower than those of the former studies [26] [27]. Although, ratio of the MERFLs having $100 \%$ similarity to the reference MERFLs with respect to the major MERFL (37\%; Tables 1-3) was lower than that of the $2^{\text {nd }}$ major MERFLs (48.0\%; Tables $\left.1-3\right)$, that of the $3^{\text {rd }}$ major MERLs (30\%) was not so lower than that of the $2^{\text {nd }}$ MERFLs and higher than those of the former studies [26]. The lower precision of the major MERFL and higher precision of the $3^{\text {rd }}$ major MERFLs was caused from lower ratio of Bacillus spp. as the followings; 8 MERFLs in colistin resistant bacteria (Table 1), 9 MERELs in chlortetracycline resistant bacteria (Table 2), and 1 MERFL in multi-drug resistant bacteria (Table 3). Because16S rDNA of Bacillus spp. was preferentially amplified and increased the relative mole concentration of the major MERFL, and decreased those of the $2^{\text {nd }}$ and $3^{\text {rd }}$ major MERFLs [26] [27], which increased the precision of the major MERFLPs, and decreased those of the $2^{\text {nd }}$ and $3^{\text {rd }}$ major MERFLPs.

\subsection{Enumeration of Each Antibiotic Resistant Bacterial Groups by Mpn}

As colistin was bactericidal to gram-negative bacteria and little to no effect on gram-positive bacteria, gram positive bacterial groups (A to C) were eliminated from antibiotic resistant bacteria (Table 4, Figure 1). Numbers of the resistant bacteria was the highest in cattle feces manure $\left(\mathrm{M} ;>3.84 \times 10^{4} \mathrm{MPN} \mathrm{g}^{-1}\right.$ dry matter), followed by row cattle feces $\left(\mathrm{R} ; 1.78 \times 10^{4} \mathrm{MPN} \mathrm{g}^{-1}\right)$, shochu lee $\left(\mathrm{S} ; 1.46 \times 10^{4} \mathrm{MPN} \mathrm{g}^{-1}\right)$, and compost originated from leftover food (L; $0.24 \times 10^{4} \mathrm{MPN} \mathrm{g}^{-1}$ ) (Figure 1). $\alpha$, $\beta$-proteobacteia (D; $1.04 \times 10^{4} \mathrm{MPN} \mathrm{g}^{-1}$ ) was the numerically dominant resistant bacteria in M, $\gamma$-proteobacteria (Pseudomonas spp. (E);0.44 $\times 10^{4} \mathrm{MPN} \mathrm{g}^{-1}$, Enterobacteriaceae (F); $0.19 \times 10^{4} \mathrm{MPN} \mathrm{g}^{-1}$, the other $\gamma$-Proteobacteria (G); $0.66 \times 10^{4} \mathrm{MPN} \mathrm{g}^{-1}$ ) was the numerically dominant in R, and $\alpha$, $\beta$-proteobacteia (D; $0.36 \times 10^{4} \mathrm{MPN} \mathrm{g}^{-1}$ ), and Pseudomonas spp. (E; $0.74 \times 10^{4} \mathrm{MPN} \mathrm{g}^{-1}$ ) were the numerically dominant in $\mathrm{S}$ (Table 4, Figure 1 ).

Numbers of chlortetracycline resistant bacteria (T) was the highest in shochu lee (S; $>320 \times 10^{4} \mathrm{MPN} \mathrm{g}^{-1}$ ),

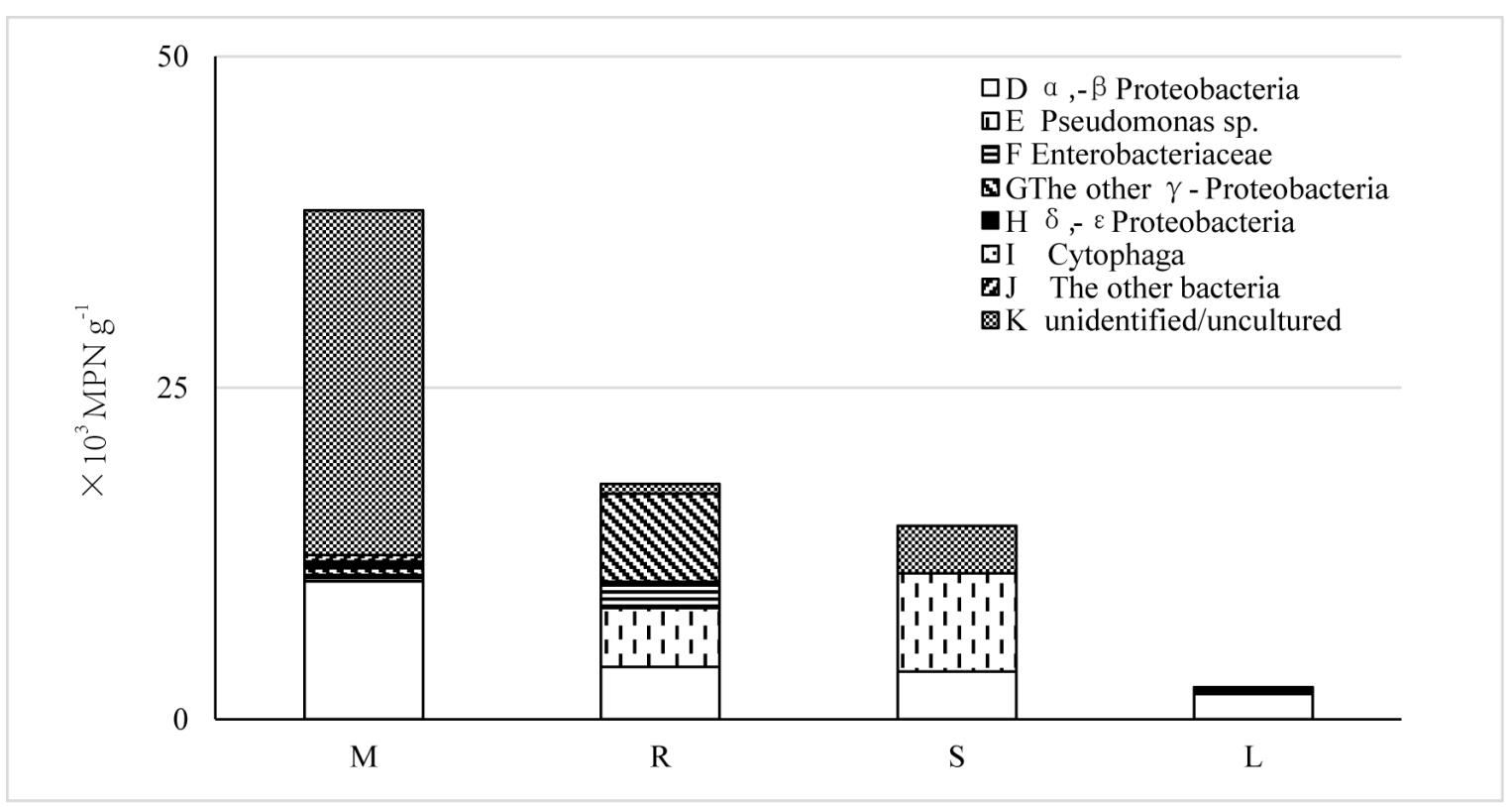

Figure 1. Numbers of colistin resistant $\left(25 \mathrm{mg} \cdot \mathrm{L}^{-1}\right)$ bacterial groups estimated by MPN and MERFLP in cattle feces manure (M), row cattle feces (R), shochu lee (S), and compost originated from leftover food (L). Number of $\alpha$, $\beta$-Proteobacteria (D; $\square$ ), Pseudomonas spp. (E; $\left[\begin{array}{l}1 \\ 1\end{array}\right)$ ), Enterobacteriacea (F; 目), the other $\gamma$-Proteobacteria (G; 8 , $\varepsilon$-Proteobacteria $(\mathrm{H} ; \mathbf{\square})$, Cytophaga $(\mathrm{I} ; \mathrm{W})$, the other bacteria $(\mathrm{J} ; \mathbb{Z})$, and unidentified or uncultured bacterial group (H; ) were presented. 
followed by compost originated from leftover food $\left(\mathrm{L} ;>44.8 \times 10^{4} \mathrm{MPN} \mathrm{g}^{-1}\right)$, row cattle feces $\left(\mathrm{R} ; 16.6 \times 10^{4}\right.$ MPN g ${ }^{-1}$ ), and cattle feces manure (M; $13.7 \times 10^{4} \mathrm{MPN} \mathrm{g}^{-1}$ ) (Table 5). In S, the other Firmucutes (C; $9.4 \times 10^{4}$ MPN), Pseudomonas spp. (E; $9.4 \times 10^{4} \mathrm{MPN} \mathrm{g}^{-1}$ ), and the other bacterial group (J; $18.6 \times 10^{4} \mathrm{MPN}$, including Mycoplasma spp), were the numerically dominant (Table 5, Figure 2). As 7 MERELs of Pseudomonas spp. (E) in $\mathrm{S}$ having the same MERFLs, they might proliferate preferentially than the other bacterial groups in $\mathrm{S}$ (Table 2). As Pseudomonas spp. (E) were the numerically dominant $\left(>36.4 \times 10^{4} \mathrm{MPN} \mathrm{g}^{-1}\right)$ in L (Table 5) and 8 MERFLs of them also having the same MERFLs (Table 2), they might also proliferate preferentially in L. As Enterobacteriacea (F; $15.7 \times 10^{4} \mathrm{MPN} \mathrm{g}^{-1}$ ) was the numerically dominant in R (Table 5) and 8 MERFLs of them also having the same MERFLs (Table 2), they might also proliferate preferentially in $\mathrm{R}$ (Table 2).

Numbers of multi drug resistant bacteria (X) was the highest in row cattle feces (R; $>143.6 \times 10^{4} \mathrm{MPN} \mathrm{g}^{-1}$ ), followed by cattle feces manure (M; $4.19 \times 10^{4} \mathrm{MPN} \mathrm{g}^{-1}$ ), and shochu lee (S; $0.36 \times 10^{4} \mathrm{MPN} \mathrm{g}^{-1}$ ) (Table 6, Figure 3). In R, the other Firmicutes (C; $36.4 \times 10^{4} \mathrm{MPN} \mathrm{g}^{-1}$ ), including Clostridium sp, and Streptcoccus sp, the other $\gamma$-proteobacteria (G; $10.3 \times 10^{4} \mathrm{MPN} \mathrm{g}^{-1}$ ), and the other bacteria (J; $10.3 \times 10^{4} \mathrm{MPN} \mathrm{g}^{-1}$ ), including Spiroplasma sp, were the numerically dominant bacterial groups (Table 3, Table 6), while there was no bacteria which proliferated preferentially in R (Table 3). As Pseudomonas sp. (E; $0.88 \times 10^{4} \mathrm{MPN} \mathrm{g}^{-1}$ ) was the numerically dominant in M (Table 3, Table 6) and 4 MERFLs and 3 MERFLs of them had the same MERFLs, they were supposed to proliferate preferentially in M (Table 3).

\section{Discussion}

In the former studies, we had detected and enumerated polymyxin B resistant bacteria not only in field soils where liquid livestock feces had annually been applied [35] [36] but also in a paddy field soil where organic manure had annually been applied [26], although polymyxin B have mainly been used in hospitals and have never been used as AGP and there was no-report of the resistant bacteria except for nosocomial resistant bacteria in hospital [37]. Colistin (polymyxin E), which had a similar structure and the same site of action [37], had been used as AGP in Japan. The sample included diverse kinds of the resistant bacteria and no-specific numerically dominant bacterial group (Table 1), which might be caused from gradual proliferation of diverse kinds of bacteria having the lower resistance by a continual sub-therapeutic administration of the antibiotic as AGP. As higher

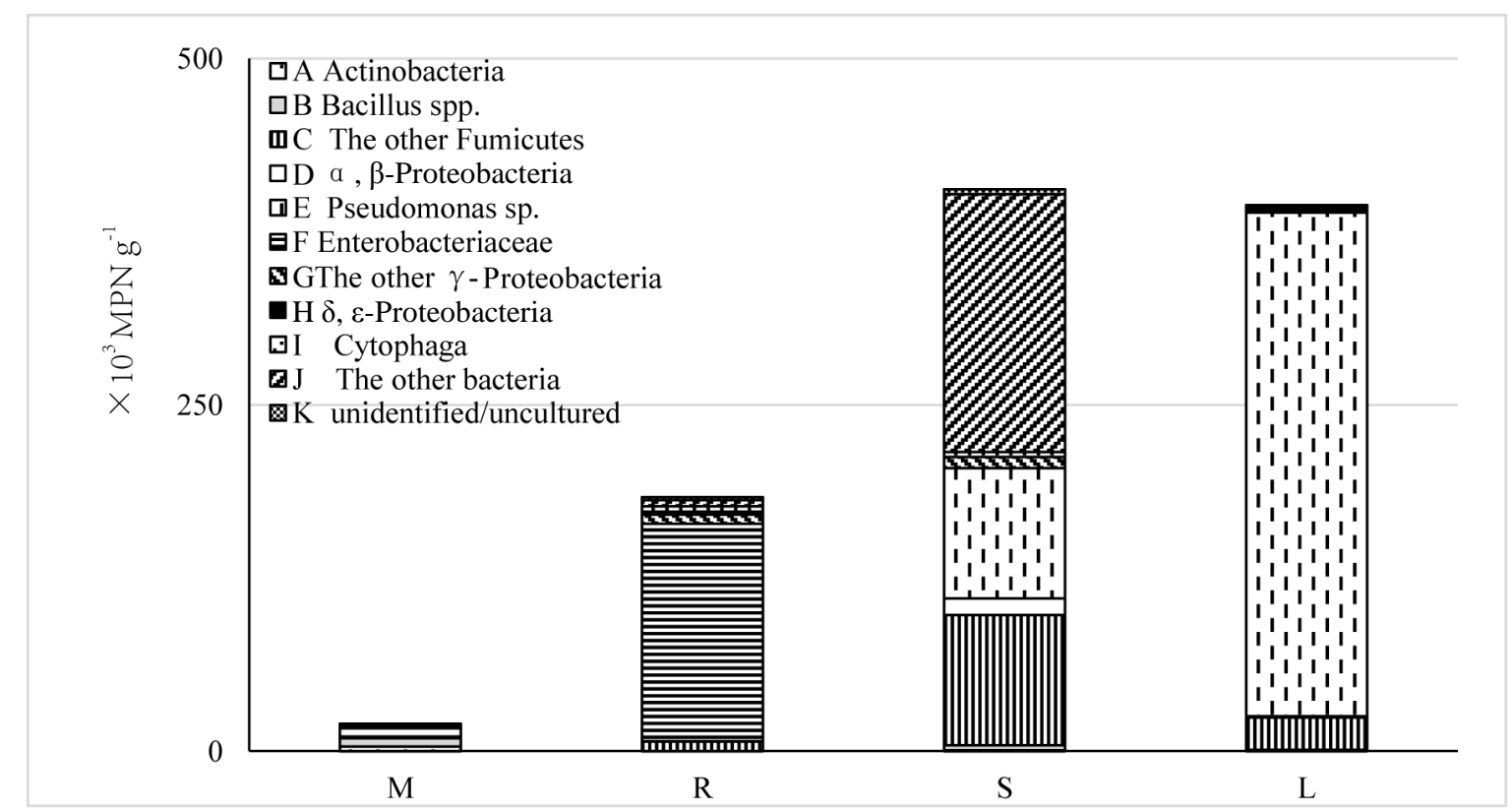

Figure 2. Numbers of chlortetracycline resistant $\left(25 \mathrm{mg} \cdot \mathrm{L}^{-1}\right)$ bacterial groups estimated by MPN and MERFLP in cattle feces manure $(M)$, row cattle feces (R), shochu lee (S), and compost originated from leftover food (L). Number of Actinobacteria (A; $\square$ ), Bacillus spp. (B; $\square$ ), the other Firmicutes (C; $\mathbb{l}$ ), $\alpha, \beta$-Proteobacteria (D; $\square$ ), Pseudomonas $\mathrm{spp}$. (E; 淀,

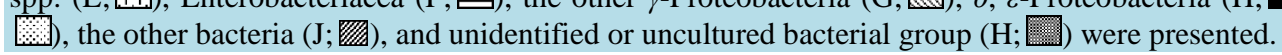


dosage of the antibiotics was used in this study $\left(25 \mathrm{mg} \cdot \mathrm{L}^{-1}\right)$ than those in the former studies $\left(5 \mathrm{mg} \cdot \mathrm{L}^{-1}\right)$, estimated numbers of the resistant bacteria in cattle feces manure $\left(\mathrm{M} ;>3.84 \times 10^{4} \mathrm{MPN}\right)$, and row cattle feces (R; $\left.1.78 \times 10^{4} \mathrm{MPN}\right)$ were lower than those estimated for the manure applied field soil $\left(3.11 \times 10^{6} \mathrm{MPN} \mathrm{g}^{-1}\right)$ [26] and those for field soils applied with liquid livestock feces (from $31.7 \times 10^{6} \mathrm{CFU} \mathrm{g}^{-1}$ to $258 \times 10^{6} \mathrm{CFU} \mathrm{g}^{-1}$ ) [35] [36]. Although numerically dominant bacterial groups in $\mathrm{M}$ (unidentified bacterial group, $\alpha, \beta$-proteobacteria; Table 1, Table 4) were different from those of upland field soil (Prevotella spp. and Cytophagales) [26], colistin resistant gram negative bacteria detected in $\mathrm{R}$ and $\mathrm{M}$ in this study were concluded to be polymyxin $\mathrm{B}$ resistant bacteria in the former studies [26] [35] [36]. The antibiotic bacteria detected and enumerated in this study were supposed to have higher resistance to colistin than those of the former studies [26] [35] [36], and those of the reported resistant bacteria [37] because they could proliferate higher concentration $\left(25 \mathrm{mg} \cdot \mathrm{L}^{-1}\right)$ than the reported resistance breakpoints for Acinetobacter spp. $\left(>2\right.$ or $\left.4 \mathrm{mg} \cdot \mathrm{L}^{-1}\right)$, that for Pseudomonas spp. $\left(>4 \mathrm{mg} \cdot \mathrm{L}^{-1}\right)$, and that for Enterobacteriacea $\left(>2 \mathrm{mg} \cdot \mathrm{L}^{-1}\right)$ [14] [37].

As chlortetracycline has widely been used for the past forty years as therapeutic agent for human and veterinary medicine but also as AGP, their numbers were higher than those of colistin resistant bacteria (Table 4, Table 5, Figure 1, Figure 2), which was coincident with the other report [14]. Although the numbers were underestimated due to an absence of MPN dilution vial higher than $10^{-6}$, the numbers were higher in shochu lee $\left(\mathrm{S} ;>320 \times 10^{4} \mathrm{MPN} \mathrm{g}^{-1}\right.$ ) and compost originated from leftover food $\left(\mathrm{L} ;>44.8 \times 10^{4} \mathrm{MPN} \mathrm{g}^{-1}\right.$ ) (Table 5, Figure 2), where Pseudomonas spp. was not only the numerically dominant microorganisms but also proliferated preferentially (Table 2, Table 5). In row cattle feces (R), specific resistant bacteria, Pantoea sp. or Xenorhobdus doucetiae, occupied the entire resistant bacterial group (Table 2, Table 5), which might suggest that therapeutic application of higher dosage of the antibiotic resulted in a rapid proliferation of this bacterial group in the cattle intestine. Although total number of the resistant bacteria in cattle feces manure $\left(\mathrm{M} ;>13.7 \times 10^{4} \mathrm{MPN} \mathrm{g}^{-1}\right)$ were lower than those of the others (Table 5, Figure 2), the composition of the resistant bacterial groups (Table 2) were similar to those in the reported field soils, where continuous application of organic manure was supposed to cause accumulation of the resistant bacteria due to sub therapeutic use of the antibiotic as AGP [18]. As the concentration of applied chlortetracycline $\left(25 \mathrm{mg} \cdot \mathrm{L}^{-1}\right)$ was as the same level as those of the reported resistance breakpoints for Salmonella spp., E. coli, Camphylobacter spp., and Enterococcus spp. (>16 mg. $\mathrm{L}^{-1}$ ) [14], the

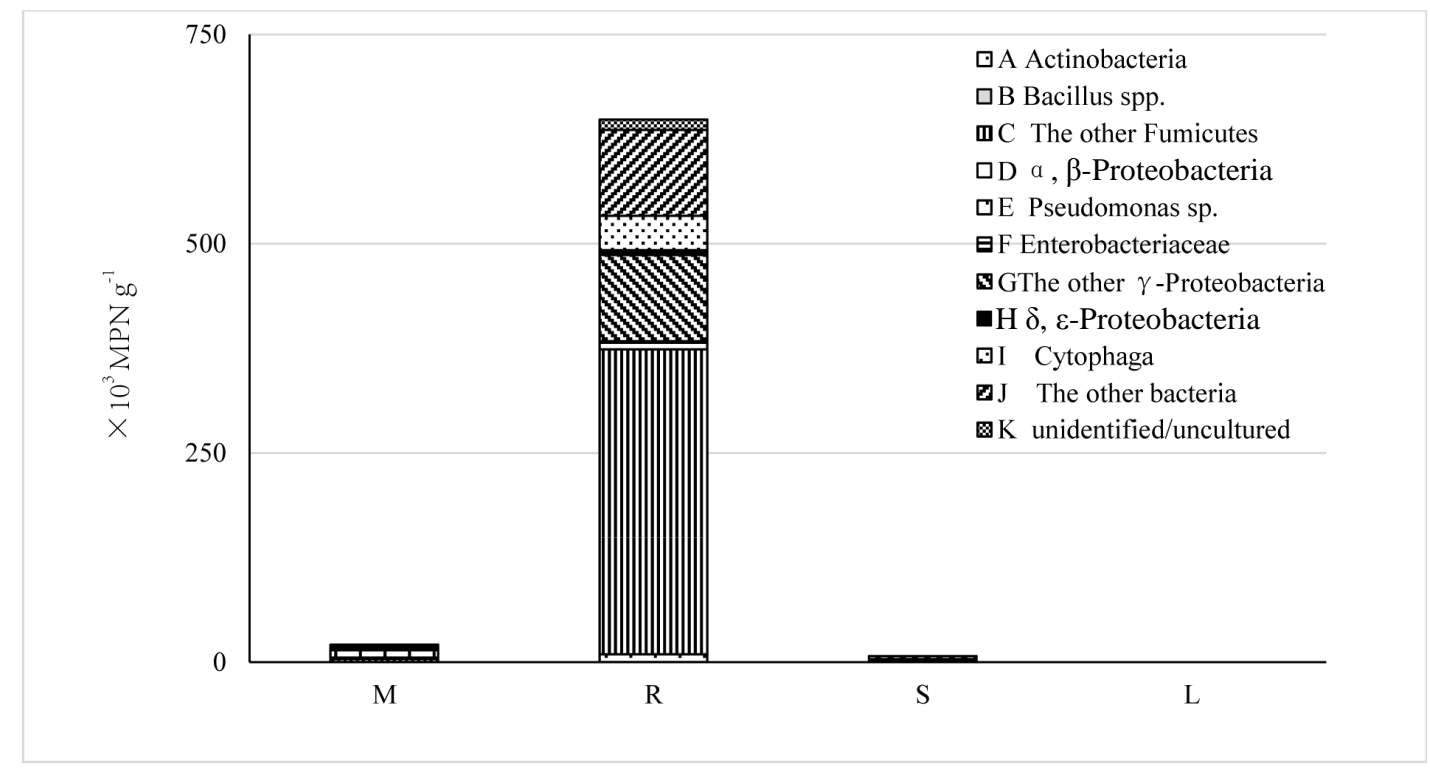

Figure 3. Numbers of multi drug, ciprofloxacin $\left(25 \mathrm{mg} \cdot \mathrm{L}^{-1}\right)$, streptomycin $\left(25 \mathrm{mg} \cdot \mathrm{L}^{-1}\right)$, chloramphenicol (25 $\left.\mathrm{mg} \cdot \mathrm{L}^{-1}\right)$, and ampicillin $\left(25 \mathrm{mg} \cdot \mathrm{L}^{-1}\right)$, resistant bacterial groups estimated by MPN and MERFLP in cattle feces manure (M), row cattle feces (R), shochu lee (S), and compost originated from leftover food (L). Number of Actinobacteria (A; $\square$ ), Bacillus spp. (B; $\square$ ), the other Firmicutes (C; 10 ), $\alpha, \beta$-Proteobacteria (D; $\square$ ), Pseu-

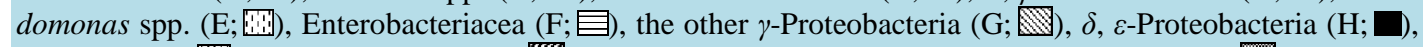
Cytophaga $(\mathrm{I} ; \mathbf{0})$, the other bacteria $(\mathrm{J} ; \mathbb{Z}$ ), and unidentified or uncultured bacterial group $(\mathrm{H} ; \square)$ were presented. 
enumerated resistant bacteria was estimated to be as same as the reported chlortetracycline resistant bacteria [14] [18] [25].

Although the numbers were underestimated due to lack of MPN dilution vial higher than $10^{-6}$, multi drug resistant bacteria was typically observed in row cattle feces (R) (Table 6, Figure 3). As their numbers in cattle feces manure (M) was 3\% of that in R (Table 6), the most of the multi drug resistant bacterial groups in row feces might decrease during manuring process. Concentration of the used ampicillin $\left(25 \mathrm{mg} \cdot \mathrm{L}^{-1}\right)$ was higher than that of the reported resistance breakpoints for Haemophilus influenzae, Listeria monocytogenes, Neisseria meningitidis, and Pasteurella multocida $\left(>1 \mathrm{mg} \cdot \mathrm{L}^{-1}\right)$, those for Streptococcus pneumoniae, and Enterobacteriacea $\left(>2 \mathrm{mg} \cdot \mathrm{L}^{-1}\right)$, and those for Entrococcus spp. $\left(>8 \mathrm{mg} \cdot \mathrm{L}^{-1}\right)$ [14] [37]. Concentration of the used chloramphenicol $\left(25 \mathrm{mg} \cdot \mathrm{L}^{-1}\right)$ was also higher than those for Haemophilus influenzae, and Moraxella catarrhalis $(>2$ $\mathrm{mg} \cdot \mathrm{L}^{-1}$ ), those for Neisseria meningitidis $\left(>4 \mathrm{mg} \cdot \mathrm{L}^{-1}\right.$ ), those for Enterobacteriacea, Staphylococus spp, and Streptococcus pneumoniae $\left(>8 \mathrm{mg} \cdot \mathrm{L}^{-1}\right)$ [37]. Concentration of the used ciprofloxacin $\left(25 \mathrm{mg} \cdot \mathrm{L}^{-1}\right)$ was much higher than those for Neisseria meningitidis $\left(>0.03 \mathrm{mg} \cdot \mathrm{L}^{-1}\right)$, those for $N$. gonorrhoeae, and Pasteurella multocida $\left(>0.06 \mathrm{mg} \cdot \mathrm{L}^{-1}\right)$, those for Haemophilus influenzae, Moraxella catarrhalis, and Camphylobacter jejuni/coli $\left(>0.5 \mathrm{mg} \cdot \mathrm{L}^{-1}\right.$ ), those for Enterobacteriacea, Pseudomonas spp, Acintobacter spp, Staphylococus spp, and Corynebacterium spp. (>1 mg. $\left.\mathrm{L}^{-1}\right)$, those for Streptococcus pneumoniae $\left(>2 \mathrm{mg} \cdot \mathrm{L}^{-1}\right)$, and Entrococcus spp. (>4 $\left.\mathrm{mg} \cdot \mathrm{L}^{-1}\right)$ [37]. While concentration of the used streptomycin $\left(25 \mathrm{mg} \cdot \mathrm{L}^{-1}\right)$ was lower than those for Salmonella spp. and E. coli $\left(>64 \mathrm{mg} \cdot \mathrm{L}^{-1}\right)$, or Enterococcus spp. $\left(>1000 \mathrm{mg} \cdot \mathrm{L}^{-1}\right)$ [14], the detected bacteria by the method was estimated to be one of the multi drug resistant bacteria. As the bacteria detected by this method had survived and proliferated under co-application of higher concentrations of these antibiotics, they might have higher resistance than those detected by the ordinal susceptibility tests where each antibiotic was separately applied for evaluation [3] [4] [7] [15] [17] [37] [38].

\section{Conclusions}

Until now the risk of antibiotic resistant bacteria has mainly been evaluated by the susceptibility tests using isolates [7]-[18] or by using selective primer of resistant gene [5] [22]-[25]. Although the susceptibility test was indispensable to search what kinds of antibiotics were effective for specific bacterial group, it was difficult to use the method for the environmental risk assessment. Because the susceptibility tests and taxonomy determinations had to be expanded broadly over a large numbers of environmentally important bacterial groups, and it was difficult to estimate numbers of the resistant bacterial group from these isolates due to the isolation bias [7]-[18]. Although the spreading of antibiotic resistant gene into various environments could be monitored by tracing resistant gene [22]-[25], the molecular-based analysis method could not be used for their environmental risk assessment because detected resistant gene had no relation to their phylogenetic positions nor phenotypic properties.

Method presented here had the following superior properties as monitoring method for the antibiotic resistant hbacteria spreading into various environment, although some bacterial groups might be underestimated as described previously [26] [27]; 1) We could easily know what kinds of antibiotics had higher risk for emergence of resistant bacteria by changing the kinds and combinations of applied antibiotics without preliminary information [26]. 2) We could easily know the environment where the number of the antibiotic resistant bacteria was high. Because false-negative results could be removed by using microbial DNA extracted after proliferation in the growth medium and decimal dilution vials of MPN where the effect PCR inhibiting substances included in various environmental samples decreased as described previously [26] [27]. 3) Because the susceptibility tests using bacterial isolates were not required for the monitoring, the risk of their community acquired infection might be evaluated safely by using it as stand-alone method.

The present results indicated that multi drug resistant bacteria might widely be spreading through animal husbandry. Their reduction method and spreading into environment will be presented in the following manuscripts by using this method.

\section{Acknowledgements}

The most of this work had been achieved in Research Team for Biomass Recycling System, National Agricultural Research Center for Kyushu-Okinawa Region. The author thanks Prof. H. Tamura, and Dr. A. Hosoda, Meijyo University, Dr. H. Yosikawa, the former Prof. of Fukuoka Institute of Technology for their suggestions and encouragements during this work. 


\section{References}

[1] World Health Organization (2012) The Evolving Threat of Antimicrobial Resistance: Options for Action. WHO, Geneva. http://www.who.int/patientsafety/implementation/amr/publication/en/

[2] Canadian Integrated Program for Antimicrobial Resistance Surveillance (2005) Canadian Integrated Program for Antimicrobial Resistance Surveillance Annual Report (2003). Health Canada, Ottawa. http://www.phac-aspc.gc.ca/cipars-picra/2012/index-eng.php

[3] Jorgensen, J.H. and Ferraro, M.J. (1998) Antimicrobial Susceptibility Testing: General Principles and Contemporary Practices. Clinical Infectious Diseases, 26, 973-980. http://dx.doi.org/10.1086/513938

[4] Jorgensen, J.H. and Ferraro, M.J. (2009) Antimicrobial Susceptibility Testing: A Review of General Principles and Contemporary Practices. Clinical Infectious Diseases, 49, 1749-1755. http://dx.doi.org/10.1086/647952

[5] Samra, Z.Q., Naseem, M., Khan, S.J., Dar, N. and Athar, M.A. (2009) PCR targeting of Antibiotic Resistant Bacteria in Public Drinking Water of Lahore Metropolitan, Pakistan. Biomedical and Environmental Sciences, 22, 458-463. http://dx.doi.org/10.1016/S0895-3988(10)60002-5

[6] Armstrong, J.L., Shigeno, D.S., Calomiris, J.J. and Seidler, R.J. (1981) Antibiotic-Resistant Bacteria in Drinking Water. Applied and Environmental Microbiology, 42, 277-283.

[7] Blaak, H., Lynch, G., Italiaander, R., Hamidjaja, R.A., Schets, F.M. and de Roda Husman, A.M. (2015) MultidrugResistant and Extended Spectrum Beta-Lactamase-Producing Escherichia coli in Dutch Surface Water and Wastewater. PLoS ONE, 10, e0127752. http://dx.doi.org/10.1371/journal.pone.0127752

[8] Oluyege, J.O., Oluwaniyi, T.T. and Ijasan, O.C. (2015) Composition of Antibiotic Resistant Bacteria from Irrigated Vegetable Farmland. Journal of Microbiology Research, 5, 161-168.

[9] Chellapandi, K., Ralte, L., Malsawmtluangi, L., Masih, L., Singh, K.K. and Boro, D. (2015) Assessing Prevalence of Antibiotic Resistant Microbes on Fresh Marketed Vegetables of Aizawl City. Malaysian Journal of Microbiology, 11, 40-46.

[10] Nipa, M.N., Mazumdar, R.M., Hasan, M.M., Fakruddin, M., Islam, S., Bhuiyan, H.R. and Iqbal, A. (2011) Prevalence of Multi Drug Resistant Bacteria on Raw Salad Vegetables Sold in Major Markets of Chittagong City, Bangladesh. Middle-East Journal of Scientific Research, 10, 70-77.

[11] Mahami, T., Odonkor, S., Yaro, M. and Adu-Gyamfi, A. (2011) Prevalence of Antibiotic Resistant Bacteria in Milk Sold in Accra. International Research Journal of Microbiology, 2, 126-132.

[12] Munsch-Alatossava, P. and Alatossava, T. (2007) Antibiotic Resistance of Raw-Milk-Associated Psychrotrophic Bacteria. Microbiological Research, 162, 115-123. http://dx.doi.org/10.1016/j.micres.2006.01.015

[13] Kilonzo-Nthenge, A., Rotich, E. and Nahashon, S.N. (2013) Evaluation of Drug-Resistant Enterobacteriaceae in Retail Poultry and Beef. Poultry Science, 92, 1098-1107. http://dx.doi.org/10.3382/ps.2012-02581

[14] USDA (2011) NARMS USDA 2011 Report. http://www.ars.usda.gov/Main/docs.htm?docid=6750

[15] Sawant, A.A., Hegde, N.V., Straley, B.A., Donaldson, S.C., Love, B.C., Knabel, S.J. and Jayarao, B.M. (2007) Antimicrobial-Resistant Enteric Bacteria from Dairy Cattle. Applied and Environmental Microbiology, 73, 156-163. http://dx.doi.org/10.1128/AEM.01551-06

[16] Burgos, J.M., Ellington, B.A. and Varela, M.F. (2005) Presence of Multidrug Resistant Enteric Bacteria in Dairy Farm Topsoil. Journal of Dairy Science, 88, 1391-1398. http://dx.doi.org/10.3168/jds.S0022-0302(05)72806-X

[17] DebMandal, M., Mandal, S. and Pal, N.K. (2011) Antibiotic Resistance Prevalence and Pattern in Environmental Bacterial Isolates. The Open Antimicrobial Agents Journal, 3, 45-52. http://dx.doi.org/10.2174/1876518101103010045

[18] Ghosh, S. and LaPara, T.M. (2007) The Effects of Subtherapeutic Antibiotic Use in Farm Animals on the Proliferation and Persistence of Antibiotic Resistance among Soil Bacteria. Multidisciplinary Journal of Microbial Ecology, 1, 191-203. http://dx.doi.org/10.1038/ismej.2007.31

[19] Hu, H., Johani. K., Gosbell, I.B., Jacombs, A.S.W., Almatroudi, A., Whiteley, G.S., Deva, A.K., Jensen, S. and Vickery, K. (2015) Intensive Care Unit Environmental Surfaces Are Contaminated by Multidrug-Resistant Bacteria in Biofilms: Combined Results of Conventional Culture, Pyrosequencing, Scanning Electron Microscopy, and Confocal Laser Microscopy. Journal of Hospital Infection, 91, 35-44. http://dx.doi.org/10.1016/j.jhin.2015.05.016

[20] Durso, L.M., Miller, D.N. and Wienhold, B.J. (2012) Distribution and Quantification of Antibiotic Resistant Genes and Bacteria across Agricultural and Non-Agricultural Metagenomes. PLOS ONE, 7, e48325. http://dx.doi.org/10.1371/journal.pone.0048325

[21] Wichmann, F., Udikovic-Kolic, N., Andrew, S. and Handelsman, J. (2014) Diverse Antibiotic Resistance Genes in Dairy Cow Manure. mBio, 5, e01017-13. http://dx.doi.org/10.1128/mbio.01017-13

[22] Tien, M.R., Murray, Y.C., Scott, R., Sabourin, AL. and Topp E. (2014) Safely Coupling Livestock and Crop Production Systems: How Rapidly Do Antibiotic Resistance Genes Dissipate in Soil Following a Commercial Application of 
Swine or Dairy Manure? Applied and Environmental Microbiology, 80, 3258-3265. http://dx.doi.org/10.1128/AEM.00231-14

[23] Faldynova, M., Videnska, P., Havlickova, H., Sisak, F., Juricova, H., Babak, V., Steinhauser, L. and Rychlik, I. (2013) Prevalence of Antibiotic Resistance Genes in Faecal Samples from Cattle, Pigs and Poultry. Veterinarni Medicina, 58, 298-304.

[24] Zhua, Y.G., Johnson, T.A., Sua, J.Q., Qiaob, M., Guob, G.X., Stedtfeld, R.D., Hashsham, S.A. and Tiedje, J.M. (2013) Diverse and Abundant Antibiotic Resistance Genes in Chinese Swine Farms. Proceedings of the National Academy of Sciences of the United States of America, 110, 3435-3440. www.pnas.org/cgi/doi/10.1073/pnas.1222743110 http://dx.doi.org/10.1073/pnas.1222743110

[25] Holman, D.B. and Chenier, M.R. (2013) Impact of Subtherapeutic Administration of Tylosin and Chlortetracycline on Antimicrobial Resistance in Farrow-to-Finish Swine. FEMS Microbiology Ecology, 85, 1-13. http://dx.doi.org/10.1111/1574-6941.12093

[26] Watanabe, K., Horinishi, N. and Matumoto, K. (2015) Antibiotic-Resistant Bacterial Group in Field Soil Evaluated by a Newly Developed Method Based on Restriction Fragment Length Polymorphism Analysis. Advances in Microbiology, 5, 807-816. http://dx.doi.org/10.4236/aim.2015.512085

[27] Watanabe, K., Horinishi, N., Matumoto, K., Tanaka, A. and Yakushido, K. (2015) Bacterial Groups Concerned with Maturing Process in Manure Production Analyzed by a Method Based on Restriction Fragment Length Polymorphism Analysis. Advances in Microbiology, 5, 832-841. http://dx.doi.org/10.4236/aim.2015.513088

[28] Japan Livestock Industry Association (2011) Japanese Feeding Standard for Dairy Cattle. National Agriculture and Food Research Organization, Tsukuba. (In Japanese)

[29] Weidner, S., Arnold, W. and Puhler, A. (1996) Diversity of Uncultured Microorganisms Associated with the Seagrass Halophila stipulacea Estimated by Restriction Fragment Length Polymorphism Analysis of PCR-Amplified 16S rRNA Genes. Applied and Environmental Microbiology, 62, 766-771.

[30] Watanabe, K., Okuda, M. and Koga, N. (2008) A Newly Developed System Based on Multiple Enzyme Restriction Fragment Length Polymorphism-An Application to Proteolytic Bacterial Flora Analysis. Soil Science and Plant Nutrition, 54, 204-215. http://dx.doi.org/10.1111/j.1747-0765.2007.00230.x

[31] Watanabe, K. and Koga, N. (2009) Use of a Microchip Electrophoresis System for Estimation of Bacterial Phylogeny and Analysis of $\mathrm{NO}_{3}{ }^{-}$Reducing Bacterial Flora in Field Soils. Bioscience Biotechnology and Biochemistry, 73, 479-488. http://dx.doi.org/10.1271/bbb.70712

[32] Cole, J.R., Chai, B., Farris, R.J., Wang, Q., Kulam-Syed-Mohideen, A.S., McGarrell, D.M., Bandela, A.M., Cardenas, E., Garrity, G.M. and Tiedje, J.M. (2007) The Ribosomal Database Project (RDP-II): Introducing myRDP Space and Quality Controlled Public Data. Nucleic Acids Research, 35, D169-D172. http://dx.doi.org/10.1093/nar/gkl889

[33] Nei, M. and Li, W.H. (1979) Mathematical Model for Studying Genetic Variation in Terms of Restriction Endonucleases. Proceedings of the National Academy of Sciences of the United States of America, 76, 5269-5273. http://dx.doi.org/10.1073/pnas.76.10.5269

[34] Blodgett, R. (2010) FDA, Bacterial Analytical Manual, Appendix 2: Most Probable Number from Serial Dilutions. http://www.fda.gov/Food/FoodScienceResearch/LaboratoryMethods/ucm109656.htm

[35] Watanabe, K. and Niimi, H. (2005) Changes in Soil Protease Activity and Numbers of Culturable Bacteria in Upland Fields by the Application of Liquid Livestock Feces. Soil Science and Plant Nutrition, 51, 491-496. http://dx.doi.org/10.1073/pnas.76.10.5269

[36] Watanabe, K. (2008) Application of Multiple Enzyme Restriction Fragment Length Polymorphism Analysis and Microchip Electrophoresis for Estimation of Antibiotic-Tolerant Bacterial Group. Journal of Pesticide Science, 33, 249-260. http://dx.doi.org/10.1584/jpestics.G08-04

[37] Gales, A.C., Reis, A.O. and Jones, R.N. (2001) Contemporary Assessment of Antimicrobial Susceptibility Testing Methods for Polymyxin B and Colistin: Review of Available Interpretative Criteria and Quality Control Guidelines. Journal of Clinical Microbiology, 39, 183-190. http://dx.doi.org/10.1128/JCM.39.1.183-190.2001

[38] The European Committee on Antimicrobial Susceptibility Testing (2016) Breakpoint Table for Bacteria. Clinical Breakpoints, Bacteria (v 6.0). http://www.eucast.org/fileadmin/src/media/PDFs/EUCAST_files/Breakpoint_tables/v_6.0_Breakpoint_table.pdf 